\title{
Twenty-Four-Hour Observations of the Marine Boundary Layer Using Shipborne NOAA High-Resolution Doppler Lidar
}

\author{
VOLKER WULFMEYER \\ Institut für Physik und Meteorologie, Universität Hohenheim, Stuttgart, Germany \\ TiJANA JANJiĆ \\ School of Engineering and Science, International University Bremen, Bremen, Germany
}

(Manuscript received 25 July 2004, in final form 28 April 2005)

\begin{abstract}
Shipborne observations obtained with the NOAA high-resolution Doppler lidar (HRDL) during the 1999 Nauru (Nauru99) campaign were used to study the structure of the marine boundary layer (MBL) in the tropical Pacific Ocean. During a day with weak mesoscale activity, diurnal variability of the height of the convective MBL was observed using HRDL backscatter data. The observed diurnal variation in the MBL height had an amplitude of about $250 \mathrm{~m}$. Relations between the MBL height and in situ measurements of sea surface temperature as well as latent and sensible heat fluxes were examined. Good correlation was found with the sea surface temperature. The correlation with the latent heat flux was lower, and practically no correlation between the MBL height and the sensible heat and buoyancy fluxes could be detected. Horizontal wind profiles were measured using a velocity-azimuth display scan of HRDL velocity data. Strong wind shear at the top of the MBL was observed in most cases. Comparison of these results with GPS radiosonde data shows discrepancies in the wind intensity and direction, which may be due to different observation times and locations as well as due to multipath effects at the ship's platform. Vertical wind profiles corrected for ship's motion were used to derive vertical velocity variance and skewness profiles. Motion compensation had a significant effect on their shape. Normalized by the convective velocity scale and by the top of the mixed layer $z_{i}$, the variance varied between 0.45 and 0.65 at $0.4 z / z_{i}$ and decreased to 0.2 at $1.0 z / z_{i}$. The skewness ranged between 0.3 and 0.8 in the MBL and showed in almost all cases a maximum between $1.0 z / z_{i}$ and $1.1 z / z_{i}$. These profiles revealed the existence of another turbulent layer above the MBL, which was probably driven by wind shear and cloud condensation processes.
\end{abstract}

\section{Introduction}

The vertical structure of atmospheric variables in the marine boundary layer (MBL) plays an important role in the development of clouds at the top of the MBL and in the initiation and maintenance of deep convection. For instance, understanding and prediction of the diurnal cycle of rainfall over the oceans and its spatial variation remains an important open issue regarding the global water cycle (e.g., Albright et al. 1985).

An important parameter of the MBL is the MBL height that is controlled by surface forcing and entrainment at the MBL top as well as by advection. The MBL

Corresponding author address: Volker Wulfmeyer, Institut für Physik und Meteorologie, Universität Hohenheim, Garbenstr. 30, D-70599 Stuttgart, Germany.

E-mail:wulfmeye@uni-hohenheim.de dynamics influence transport, lifetimes, and diurnal cycles of particulate and gaseous trace species. Ozone is a good and extensively studied example of a gaseous substance whose diurnal variation is profoundly affected by MBL processes (Bremaud et al. 1998; Dickerson et al. 1999). Furthermore, marine aerosol particles affect radiative transfer and cloud processes in a complicated manner because of their complex vertical variability. As a consequence, detailed clear-air observations of MBL variables are essential to improve modeling and simulation of transport processes and modeling and simulation of cloud and precipitation development.

In recent years, considerable progress has been made in the development, improvement, and application of active remote sensing systems such as lidar for boundary layer research (e.g., Sullivan et al. 1998; Wulfmeyer 1999a,b; Grund et al. 2001; Mayor 2001; Mayor et al. 
2003). Lidar instruments are able to provide nearly continuous observations in the clear atmosphere. In particular, advanced lidar systems can measure profiles of key variables in the atmospheric boundary layer (ABL) such as particle backscatter, wind, and water vapor with outstanding accuracy and resolution (Wulfmeyer 1999b; Lenschow et al. 2000).

In this work, the structure of the MBL in the tropical Pacific Ocean is investigated using shipborne observations obtained with the National Oceanic and Atmospheric Administration (NOAA) high-resolution Doppler lidar (HRDL) during the 1999 Nauru (Nauru99) campaign. To our knowledge, this was the first time that a shipborne Doppler lidar was applied in this region. The operation of HRDL on a research vessel was an important test of the reliability of such a delicate system. Furthermore, this campaign offered an opportunity for developing scanning and observation strategies for boundary layer measurements using Doppler lidar.

An analysis of a 24-h time series is presented, covering the period from 0700 UTC 23 June 1999 to 0700 UTC 24 June 1999. During this observation period, large-scale forcing hardly influenced the structure of the MBL. After explaining the retrieval methods in detail, HRDL measurements of the MBL top and horizontal wind profiles are presented and analyzed. In particular, the dependence of MBL depth on surface forcing is examined. Furthermore, extended comparisons with radiosonde data are performed.

It turns out that profiles of turbulent variables can only be determined after correction for ship's motion. After introducing a new method for ship-motion correction, variance and skewness profiles of vertical velocity are derived and discussed. Comparisons of these results with previous measurements obtained with in situ sensors on airborne platforms are presented.

\section{Nauru99 intensive observation period}

The data used in this study were collected during the Nauru99 campaign, which took place from 16 June to 15 July 1999 in the tropical western Pacific. Nauru99 was a field project within the Atmospheric Radiation Measurement (ARM) Program that studied the tropical ocean and atmosphere around the island of Nauru in the central western Pacific Ocean.

One of the goals of Nauru99 was to improve our understanding of ocean surface fluxes, MBL turbulence and entrainment, and precipitation in the Tropics through land-based, air-based, and ocean-based measurements. During the campaign, observations were collected using several lidar and radar systems and a suite of different in situ sensors and radiosondes. These instruments were located on two research vessels, the Mirai and Ronald H. Brown, and on Nauru Island. The complete list of all instruments used on these three locations was available at the time of writing at the Nauru99 science and operations Web site (http://www. arm.gov/docs/iops/1999/twp1999nauru/nauru99.html). Instruments used in this study were on the NOAA research vessel Ronald H. Brown.

From 23 June to 30 June 1999, the ship was located at $2^{\circ} \mathrm{S}, 165^{\circ} \mathrm{E}$ for maintenance at a Tropical AtmosphereOcean (TAO) buoy. From this period, a 24-h series starting at 0700 UTC 23 June was chosen for analysis. During this time, no significant weather systems influenced the stationary MBL measurements in this remote area in the open tropical Pacific.

\section{HRDL setup and performance}

The HRDL was supplied by the NOAA Environmental Technology Laboratory (Wulfmeyer et al. 2000; Grund et al. 2001) to make high-resolution wind and aerosol particle measurements during the Nauru99 campaign.

The lidar consists of a frequency-stable transmitter operating on an eye-safe wavelength of $2.0218 \mu \mathrm{m}$, a high-speed scanner permitting 3D measurements of atmospheric variables in the upper hemisphere, and a detector and data acquisition system (Grund et al. 2001). The complete system is transportable in a single container.

At the time of the experiment we were aware of only one previous attempt to operate a coherent Doppler lidar on a ship platform (Grund et al. 2001). During this effort, significant instabilities of the transmitter laser frequency were found. These limited the duty cycle and, hence, the performance of boundary layer measurements.

Prior to the campaign, this experience motivated the development of a new frequency stabilization technique of the slave laser (Wulfmeyer et al. 2000). This patented technique should permit wind measurements with remarkable accuracy and resolution, even in a rough environment. Furthermore, a successful modification of the laser transmitter was performed leading to a pulse energy of $1.5 \mathrm{~mJ}$ with a repetition rate of 200 Hz. A repetition rate of $1000 \mathrm{~Hz}$ was also, in principle, possible; a bottleneck in the data acquisition system limited the data storage to repetition rates of $200 \mathrm{~Hz}$, however.

An important research goal was to examine the reliability of such a complex lidar system on a shipborne platform. If continuous, high-quality measurements 
were possible, detailed investigations of the structure of the MBL were planned. In particular, scanning strategies for extending the information about MBL variables, such as horizontal wind speed and direction, were tested. The performance and range of the system in the tropical MBL under different atmospheric conditions were also carefully examined.

HRDL uses coherent detection so that the intensity of the backscatter signal and the line-of-sight (LOS) velocity can be measured simultaneously. Velocity data were obtained by a parabolic fit to the Doppler spectrum determined using complex demodulation of the in-phase and quadrature heterodyne signals (for more details see Grund et al. 2001). The range-dependent sensitivity function of the backscatter signal was aligned to a nearly constant value by focusing the lidar beam to a range of more than $4 \mathrm{~km}$. After optimizing the alignment of the transmitter in the field of view of the receiver, no attempt was made to further optimize the overlap function. Systematic errors resulting from a slight time-dependent sensitivity as well as detector ringing were still present in the HRDL intensity measurements. For applications for which a calibration of HRDL data is required, such as the determination of the backscatter coefficient, these effects need to be corrected. For the applications presented in this paper, corrections were not necessary. The backscatter and LOS velocity data were stored with a resolution of $30 \mathrm{~m}$ and $1 \mathrm{~s}$, respectively. For deriving profiles of turbulent variables, these resolutions were used. For studying the MBL top, horizontal averaging of backscatter gradients over $1 \mathrm{~min}$ was required for reducing noise errors.

HRDL collected a large set of data in three different operation modes. Mode 1 was the vertically pointing configuration. In mode 1, high-resolution vertical profiles of the vertical wind component and backscatter intensity were obtained with a noise error in the radial velocity on the order of $10 \mathrm{~cm} \mathrm{~s}^{-1}$. Noise errors were determined using the autocovariance analysis of highresolution LOS wind time series (Wulfmeyer 1999b; Lenschow et al. 2000). The high resolution of the range and the low noise level permitted profiling of moments of vertical wind fluctuations up to the fourth order (Lenschow et al. 2000). In mode 2, velocity-azimuth display (VAD) scans were performed at the elevation angles of $5^{\circ}, 35^{\circ}$, and $50^{\circ}$. Using mode 2 , starting from low levels, vertical profiles of the horizontal wind vector were obtained throughout the MBL and, in some cases, even a few hundred meters above. Every $2 \mathrm{~h}$, the HRDL configuration was switched from mode 1 to mode 2 , and three VAD scans with $5^{\circ}, 35^{\circ}$, and $50^{\circ}$ elevation angles were performed with a scan speed of $2^{\circ}$ $\mathrm{s}^{-1}$. Each VAD scan consisted of two round-trips of the scanner. Also, horizontally pointing measurements with and without horizontal scanning were performed, which was called mode 3 . In this publication, the focus is on measurements performed in modes 1 and 2 using an elevation angle of $35^{\circ}$. In the retrieval of horizontal wind profiles, horizontal homogeneity of the atmosphere over the open ocean was assumed, which was confirmed by the large-scale analysis of the meteorological conditions (see section 4a).

During the campaign, confidence for routine operation of coherent Doppler lidars on shipborne platforms was being built. No failures were observed, so that a high duty cycle and a high temporal resolution of wind measurements were achieved. The injection seeder, an important part of the laser transmitter, was very stable and operated continuously during the campaign so that the warm-up time for starting a measurement was only about $5 \mathrm{~min}$.

After the successful operation of the shipborne Doppler lidar during Nauru99, we are not aware of further shipborne measurements using HRDL; however, the successful performance of HRDL led to the first application on an airborne platform during the International $\mathrm{H}_{2} \mathrm{O}$ Project (IHOP_2002; Hardesty et al. 2003; Weckwerth et al. 2004). Other shipborne measurements were reported using the NOAA MiniMOPA (Master Oscillator Power Amplifier), a Doppler lidar system based on a carbon dioxide laser, which was operated during the East Pacific Investigation of Climate Processes in the Coupled Ocean-Atmosphere System (EPIC) 2001 campaign (information was available online at http://www.etl.noaa.gov/programs/2001/ epic/).

\section{Analysis of the 24-h observation period}

\section{a. Weather situation and background data}

During the field campaign, mainly fair weather conditions were present. Only on about 10 days did the precipitation rate exceed $1 \mathrm{~mm} \mathrm{~h}^{-1}$. Except for a few showers, the sky was mostly clear with some scattered cumuli and high-level cirrus clouds. During the whole period from 0700 UTC 23 June 23 until 0700 UTC 24 June 1999 that will be analyzed here, a high pressure system was located close to the measurement site at $2^{\circ} \mathrm{S}, 165^{\circ} \mathrm{E}$. At this location, the local time (LT) is UTC $+12 \mathrm{~h}$. On 23 and 24 June the sunrise was at 0702 LT and the sunset was at 1902 LT.

The National Centers for Environmental PredictionNational Center for Atmospheric Research (NCEPNCAR) reanalysis for the considered period showed 

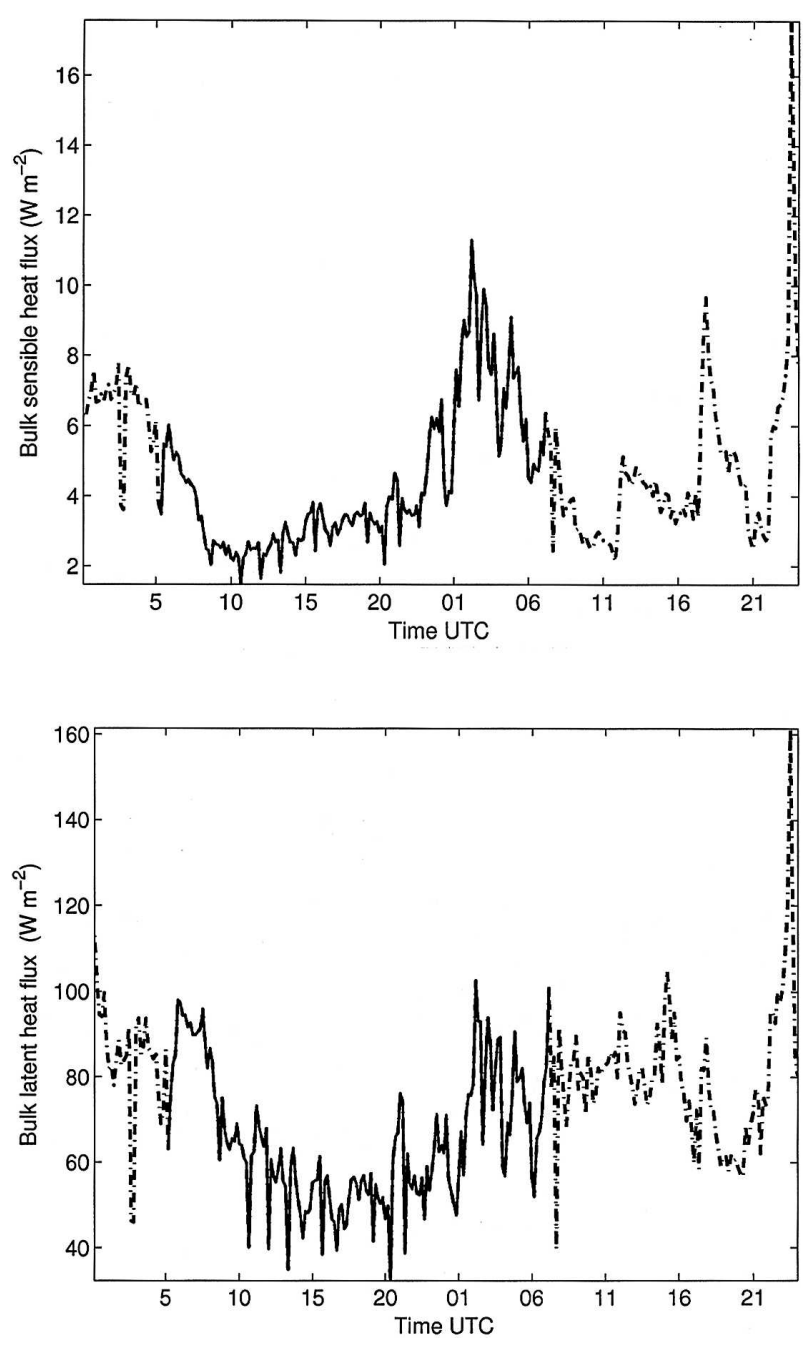

FIG. 1. (top) Sensible and (bottom) latent heat flux for 23 and 24 Jun 1999 at $2^{\circ} \mathrm{S}, 165^{\circ} \mathrm{E}$. The time period covered in this study is denoted by the full black line.

slight variation of vertical velocity at $684 \mathrm{~m}$ from 0.4 $\mathrm{cm} \mathrm{s}^{-1}$ on 0600 UTC 23 June to $-0.3 \mathrm{~cm} \mathrm{~s}^{-1}$ on 0600 UTC 24 June (figures omitted). This suggests that the effect of synoptic-scale motions on the boundary layer height was modest. The boundary layer height and turbulence were expected to be driven mainly by surface forcing and entrainment, with the latter affected by the strength of the capping inversion, wind shear at the top of the boundary layer, and gravity waves. This situation was consequently well suited for studying the diurnal variation of a well-mixed MBL with weak large-scale forcing.

The NCEP-NCAR surface reanalysis showed a wind speed of about $2 \mathrm{~m} \mathrm{~s}^{-1}$. The wind direction was east during 23 June, turning to southeast during 24 June, so that the advection of air masses from the open Pacific Ocean was always present.

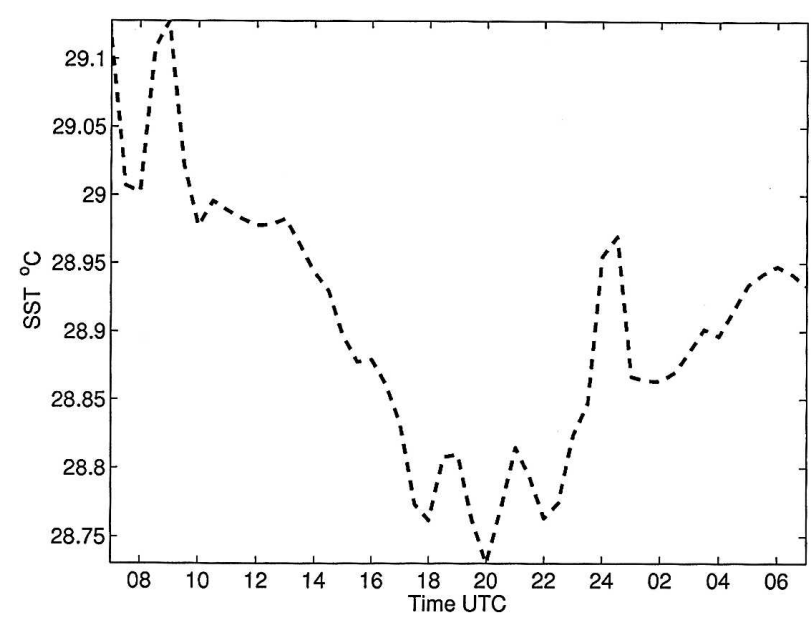

FIG. 2. SST time series during the observation period.

To describe in more detail the meteorological situation at the measurement site, we analyzed surface and radiosonde data. The surface data agreed well with the large-scale analyses. The surface horizontal wind speed was fairly low, with values between 0.6 and $2.6 \mathrm{~m} \mathrm{~s}^{-1}$. The wind direction was mainly east to southeast. The surface pressure was nearly constant with a value of about $1009 \mathrm{hPa}$. The latent and sensible heat surface fluxes were small during this time period, as can be seen from Fig. 1. The sensible heat flux was about $6 \mathrm{~W} \mathrm{~m}^{-2}$, varying by about $4 \mathrm{~W} \mathrm{~m}^{-2}$. As a consequence, during the whole observation period a weak convective boundary layer (CBL) was present. The latent heat flux was about $70 \mathrm{~W} \mathrm{~m}^{-2}$, varying between 40 and $90 \mathrm{~W} \mathrm{~m}^{-2}$. Both flux time series indicate a slight diurnal variation with maxima during daytime and minima during nighttime.

During the observation period the air temperature varied from $27.1^{\circ}$ to $28.5^{\circ} \mathrm{C}$ while the sea surface temperature (SST) changed between $28.7^{\circ}$ and $29.2^{\circ} \mathrm{C}$ (see Fig. 2). The time series of SST showed a decrease until 2000 UTC and an increase from 2000 UTC until the end of the observation period.

Every $3 \mathrm{~h}$, radiosonde profiles of virtual potential temperature, mixing ratio, and horizontal wind were available from 1100 UTC 23 June until 0500 UTC 24 June, except for relative humidity data at 0800 UTC 23 June that were missing. The corresponding data are shown in Fig. 3 with a resolution of 6 h. This is sufficient to get an overview about the variability of atmospheric conditions during the observations period.

The mixing ratio profiles (see upper right panel of Fig. 3) showed a well-mixed MBL. In the convective MBL, the value of mixing ratio increased from about 14 to about $16 \mathrm{~g} \mathrm{~kg}^{-1}$ by 2300 UTC and then varied between 15 and $16 \mathrm{~g} \mathrm{~kg}^{-1}$ for the rest of the observation 

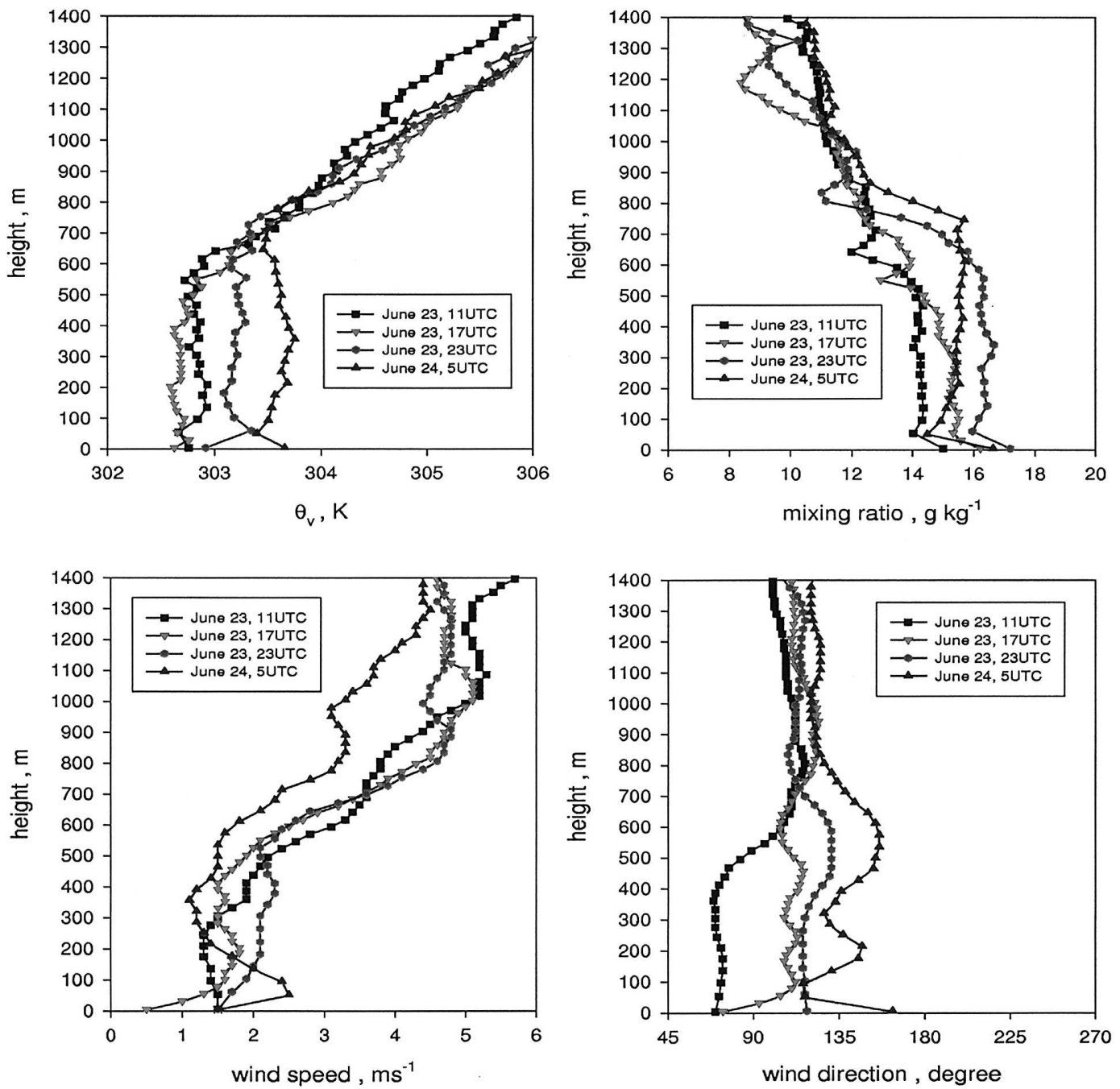

FIG. 3. Radiosonde profiles of potential temperature, mixing ratio, and horizontal wind for 23 and 24 Jun 1999 at $2^{\circ} \mathrm{S}, 165^{\circ} \mathrm{E}$.

period. The onset of a negative humidity gradient can be used as a measure of the MBL top [see section $4 \mathrm{~b}(3)]$.

The profiles of horizontal wind are presented in the lower panels of Fig. 3. Changes in the direction between 1100 and 1700 UTC on 23 June from northeastward to northwestward are evident, as expected. In the mixed layer, the wind speed varied between 1.2 and $2 \mathrm{~m} \mathrm{~s}^{-1}$. A wind shear at the MBL top is clearly visible, for example, on 230023 June at the height of $550 \mathrm{~m}$. However, irregularities of wind direction and speed in the MBL are not consistent with a well-mixed convective mixed layer (see, e.g., the wind speed and direction profiles at 050024 June). Therefore, we did not use these data for further detailed investigation of the MBL structures.

In all cases, the profiles of virtual potential tempera- ture confirmed the presence of a CBL and a pronounced inversion layer on top of it (see upper left panel of Fig. 3). In the following, we do not distinguish anymore between the CBL and the convective MBL. The values of virtual potential temperature in the mixed layer varied between 302.5 and $303.7 \mathrm{~K}$. The strength of the inversion was about $0.06 \mathrm{~K} \mathrm{~m}^{-1}$. We did not make attempts to investigate changes of these gradients because of large radiosonde sampling errors.

It was often difficult to separate the top of the inversion layer, or the top of the entrainment zone, from the free troposphere (see, e.g., the profile at 0500 UTC 24 June). Therefore, it was not possible to use consistently the center of the entrainment zone as the definition of the radiosonde-derived instantaneous MBL top $z_{R}$ (Stull 1988). Instead, here $z_{R}$ is taken to be the height corresponding to the top of the well-mixed MBL. Its 

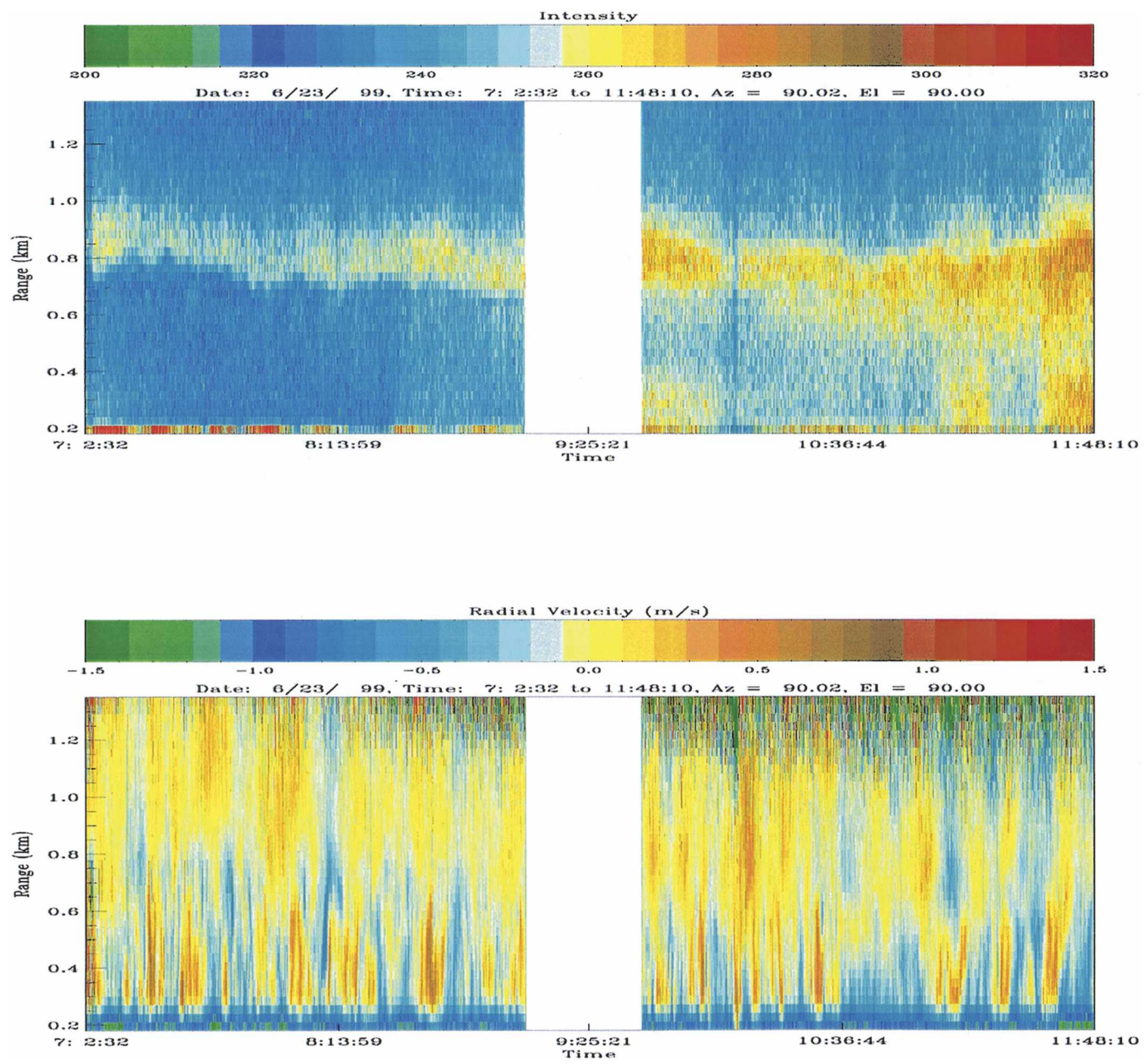

FIG. 4. (top) Time-height cross section of backscatter intensity from 0702 to 1148 UTC 23 Jun 1999. (bottom) Corresponding vertical velocity data. The white bars indicate data gaps resulting from a change to operation mode 2 .

values varied between 450 and $710 \mathrm{~m}$ throughout the observation period. These findings are supported by corresponding changes in the humidity gradient.

\section{b. Variables measured with $H R D L$}

In the following, the HRDL data, which covered the period from 0700 UTC 23 June 1999 to 0700 UTC 24 June 1999, are analyzed in detail. We are focusing on backscatter data, vertical velocity data, and horizontal wind profiles determined using VAD scans.

\section{1) BACKSCATTER AND VERTICAL VELOCITY DATA}

In the upper panels of Figs. 4-8, the whole series of time-height cross sections of the HRDL backscatter signal are presented. Data above $240 \mathrm{~m}$ are retrieved; below this height, data analysis is not reliable because of the overlap function in the near range that causes strong systematic and noise errors. The backscatter intensity was determined by plotting the zero lag of the autocovariance function of the heterodyne signal in a range cell. Because the range cell has a width of $30 \mathrm{~m}$ and the bandwidth of the receiver was $50 \mathrm{MHz}$ (Grund et al. 2001, with further references), 10 data points with a separation of $3 \mathrm{~m}$ were available for this calculation. The lower panels of Figs. 4-8 present the corresponding vertical velocity data.

The time series shows a complex situation. The MBL did not contain a higher concentration of aerosols than the free troposphere, as is usually the case (e.g., Boers 

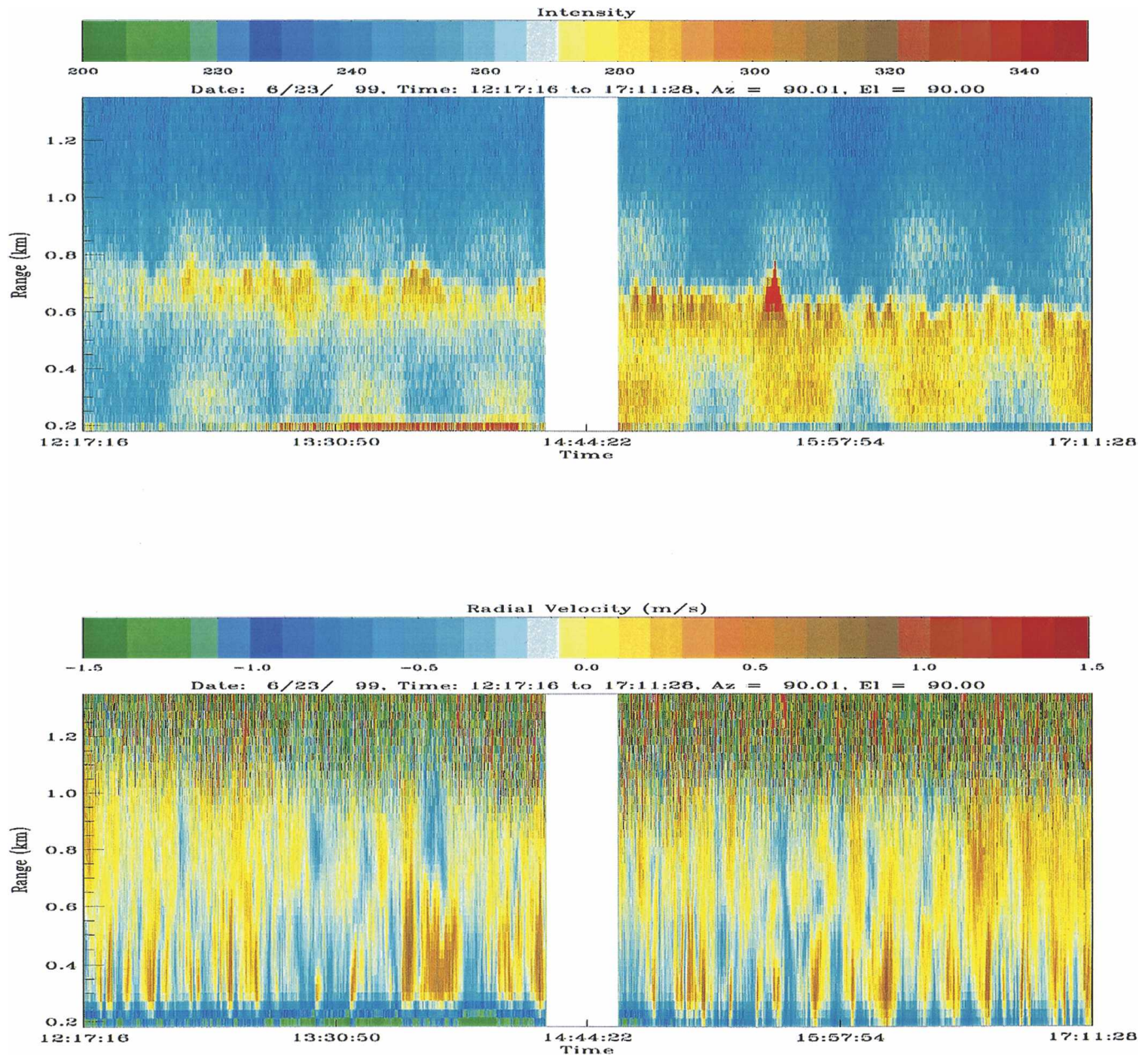

FIG. 5. As in Fig. 4, but from 1217 to 1711 UTC 23 Jun 1999.

and Eloranta 1986; Senff et al. 1994; Wulfmeyer 1999b; Cohn and Angevine 2000). In contrast, during the whole observation period, an elevated aerosol layer with a vertical extension of about $200 \mathrm{~m}$ was observed, whereas the MBL contained cleaner air, as indicated by the low and homogeneous backscatter signal. The aerosol layer descended from about $900 \mathrm{~m}$ at the beginning of the measurement period to about $600 \mathrm{~m}$ at 1730 UTC. At about 2230 UTC it started to ascend again, reaching $800 \mathrm{~m}$ at $0700 \mathrm{UTC}$ on 24 June. From about 1100 to 2000 UTC, the data show oscillations in intensity with a period of about $1 \mathrm{~h}$. The reason for this oscillation is not fully understood, but the periodicity and the increase of the signal over the entire range suggest that this is not due to atmospheric effects. We believe that this is due to temperature cycling of the air conditioning in the seatainer. This can cause slight changes in the coalignment of the laser transmitter and receiver, resulting in a subtle change of the sensitivity function. We made no attempt to correct the data for this effect.

At the beginning of the measurement, the particle layer apparently was decoupled from the MBL. It showed only weak mixing with the MBL air, as can be seen from the HRDL backscatter data. The backscatter intensity in this layer increased gradually from about 250 to 320 (arbitrary units). It is hard to identify whether this increase is due to a change of microphysical properties of aerosol particles or is due to a change of number density. The contribution from swelling of the particles is presumably small, because the radiosonde data showed relative humidities below $90 \%$ in this 

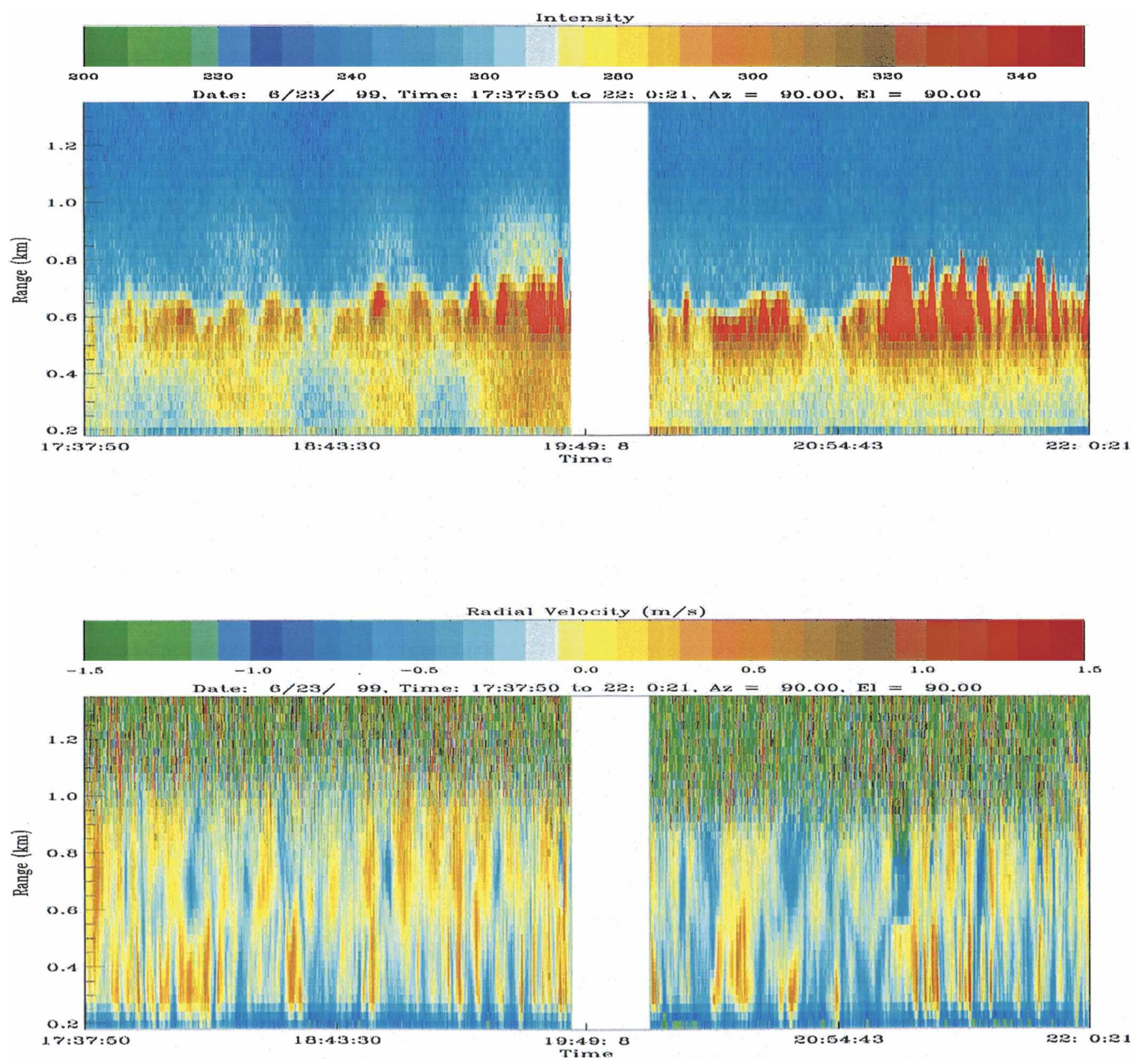

FIG. 6. As in Fig. 4, but from 1737 to 2200 UTC 23 Jun 1999.

layer. It was shown in Wulfmeyer and Feingold (2000) that a significant increase of aerosol particle backscatter takes place at relative humidities in excess of $90 \%$. During some periods, the vertical extent of enhanced backscatter caused by aerosols increased (e.g., between 2000 and 2245 UTC), indicating vertical entrainment into the MBL. Whereas at the beginning of the time series the MBL was cloud free, from 1915 UTC 23 June until the end of the observations period scattered cumulus clouds were detected embedded in the aerosol layer. The presence of these cumulus clouds was indicated by the backscatter signal overload (red regions in the upper panels of Figs. 5-8).

The corresponding vertical velocity data show the expected convective activity in the MBL. Though these measurements were affected by ship's motion [see sec- tion $4 \mathrm{~b}(4)$ ], thermal structures can be observed with moderate updrafts of $1 \mathrm{~m} \mathrm{~s}^{-1}$. The strength of convective updrafts became slightly stronger at the end of the observation period. The upper bounds of these eddies agreed well with the base of the elevated aerosol layer.

Particularly striking in the images of vertical velocity is the continuous presence of a double-layer turbulent structure. Whereas the MBL was indicated by updrafts up to a maximum height of about $800 \mathrm{~m}$ and the corresponding downdrafts, a second layer is visible that still shows a significant amount of turbulence. The vertical range of this layer extended from about 600 to more than $1200 \mathrm{~m}$ at the beginning of the measurement, and from 700 to $1200 \mathrm{~m}$ at the end of the observation period. The data indicate a strong coupling of vertical motions with similar horizontal scales except that, 

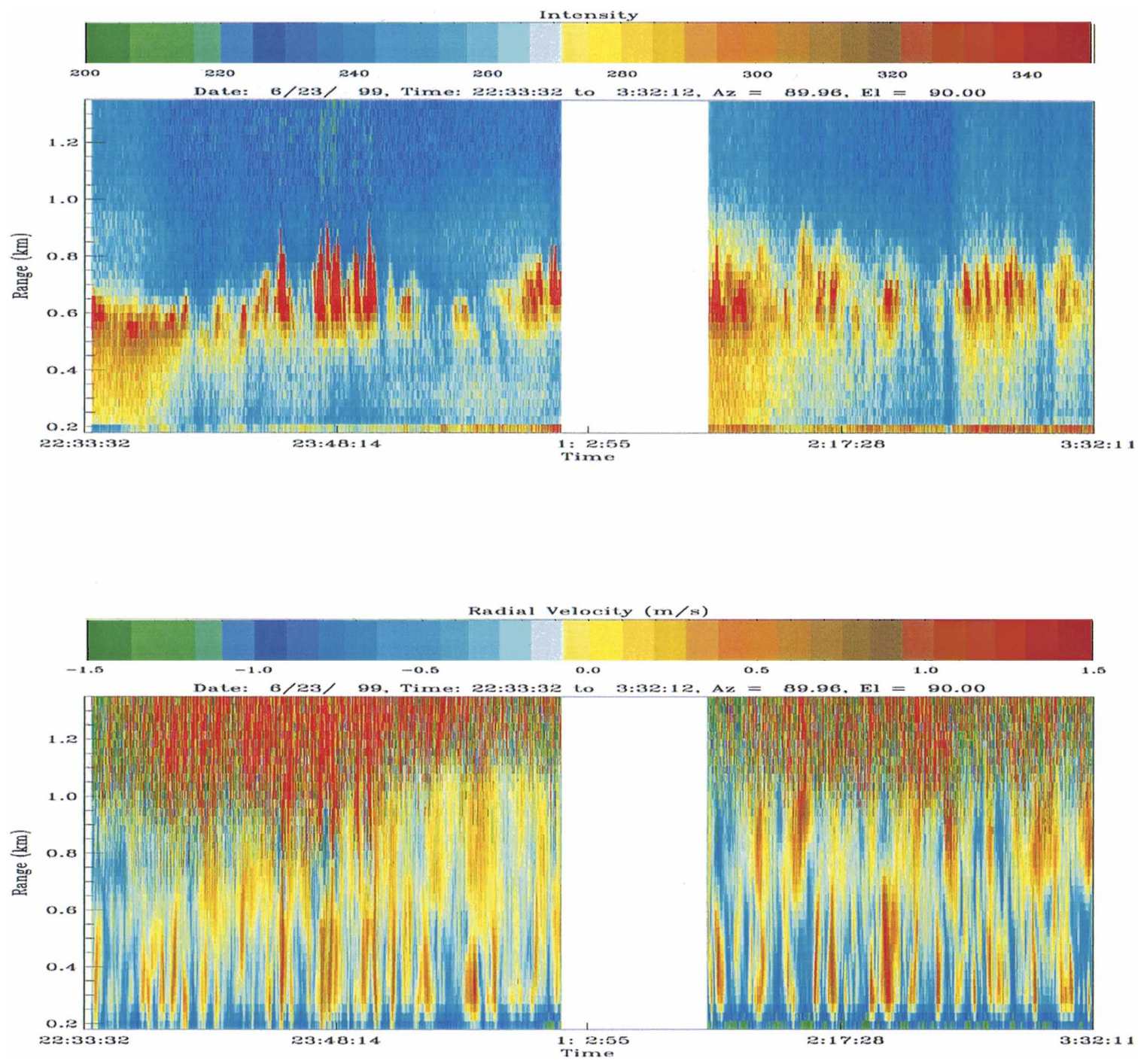

FIG. 7. As in Fig. 4, but from 223323 Jun to 0332 UTC 24 Jun 1999.

above the MBL, the strengths of updrafts and downdrafts were slightly weaker and amounted to about 0.5 $\mathrm{m} \mathrm{s}^{-1}$.

This turbulence cannot be explained by the activity of gravity waves alone. In this layer, a Brunt-Väisälä period of the order of 8 min can be expected (see Fig. 3 and Stull 1988). Frequencies lower than this may be present, but they are clearly superimposed by stochastic turbulence similar to that observed in the MBL [see also section $4 \mathrm{~b}(5)]$. Because the second layer was characterized by stable conditions and the presence of clouds, we believe that this turbulent activity was driven by wind shear and cloud condensation. The observation of this layer is not new. It was documented in several publications (Albrecht 1979; Cotton et al. 1995; Russell et al. 1998). However, we are not aware that this structure has yet been observed and analyzed using Doppler lidar. A further discussion of the turbulent properties of this layer is given in section 5c.

The HRDL vertical velocity data have been used for the investigation of moments of vertical velocity [see section $4 \mathrm{~b}(5)]$. However, because the HRDL platform was not stabilized, these data were first corrected for the motion of the ship as described in section $4 b(4)$.

\section{2) Horizontal Wind PROFILES}

Using VAD scans of the HRDL data, profiles of horizontal velocity were derived. The horizontal wind values as a function of range were determined by fitting a sine function to the LOS velocity, including rms error analysis. The LOS velocity is the projection of the wind vector to the lidar beam direction, which is measured by 

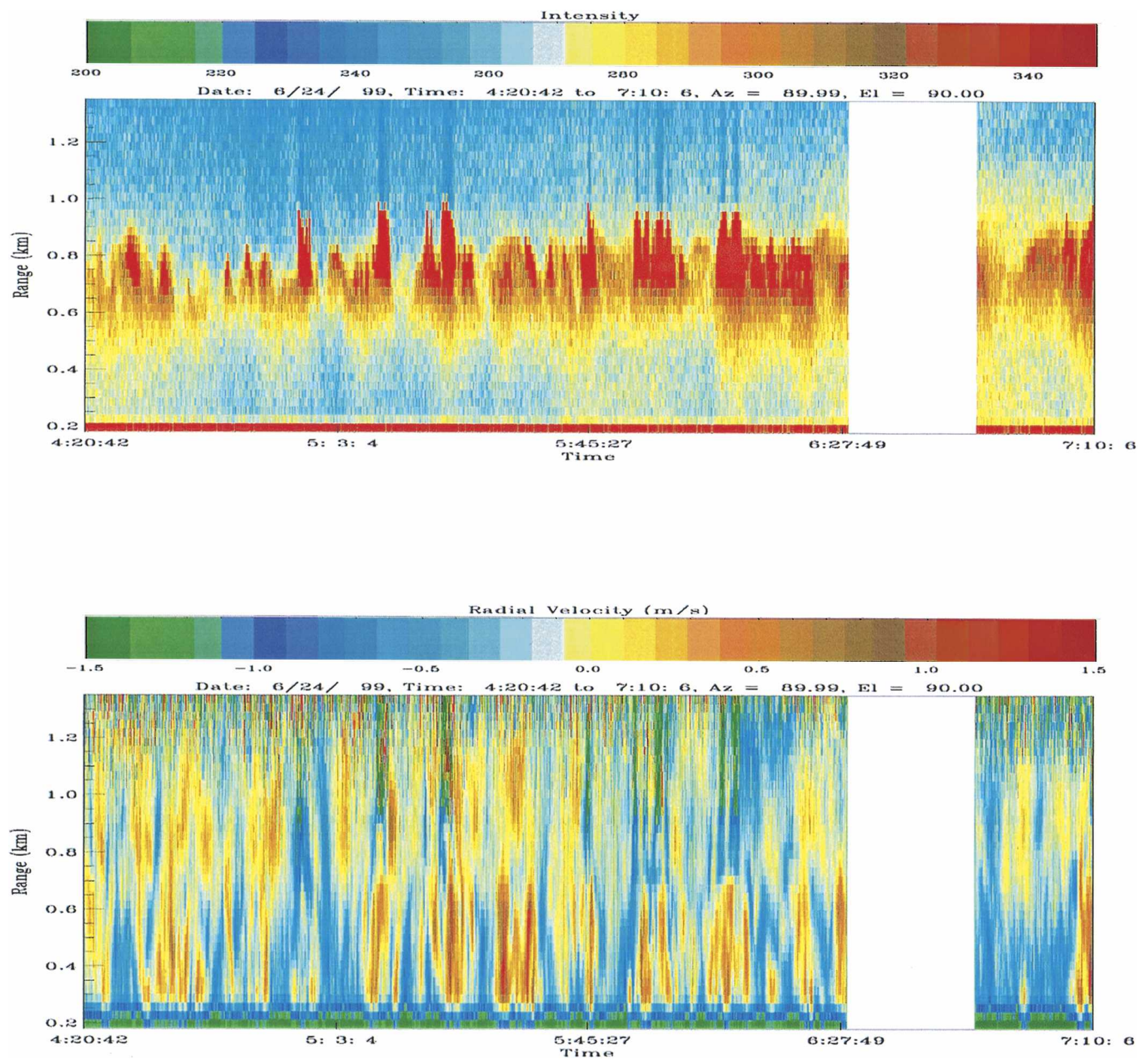

FIG. 8. As in Fig. 4, but from 0420 to 0710 UTC 24 Jun 1999.

the Doppler shift. Details of this well-established technique are discussed in Eberhard et al. (1989), and recent results are discussed in Reitebuch et al. (2001). Figures 9 and 10 show examples of profiles of the wind speed (left panel) and direction (right panel). For the example of 0926 UTC 23 June, presented in Fig. 9, the MBL is indicated by a nearly constant wind speed and direction above $200 \mathrm{~m}$, with values around $3 \mathrm{~m} \mathrm{~s}^{-1}$ and $85^{\circ}$. At the top of the MBL, significant wind shears were observed with changes in the wind speed of about $0.8 \mathrm{~m} \mathrm{~s}^{-1}$ per $30 \mathrm{~m}$ and in the wind direction of about $15^{\circ}$ per $40 \mathrm{~m}$. Note that for almost all of the profiles presented in Figs. 9 and 10, the location of the increase of wind speed agrees well with the height of the base of the aerosol layer detected in Figs. 4-8. If the height of this base, the increase of wind speed, and/or the change of wind direction were used to estimate the MBL depth, a continuous decrease of the MBL depth from the beginning of the measurement period until 1952 UTC 23 June would be observed in both datasets.

\section{3) Determination of MBL DePTH}

One of the most important variables characterizing the MBL is its mean depth. The height of the MBL $z_{i}$ is a common scaling variable (Stull 1988) that reflects the strength of the turbulent activity. Therefore, it is important to estimate this variable with high resolution and accuracy. Because the MBL is often associated with clouds, several definitions of its height can be found in the literature. Following Garratt (1992), here $z_{i}$ is defined to be at or near the cloud base. This depth scale has been considered the most appropriate for the 

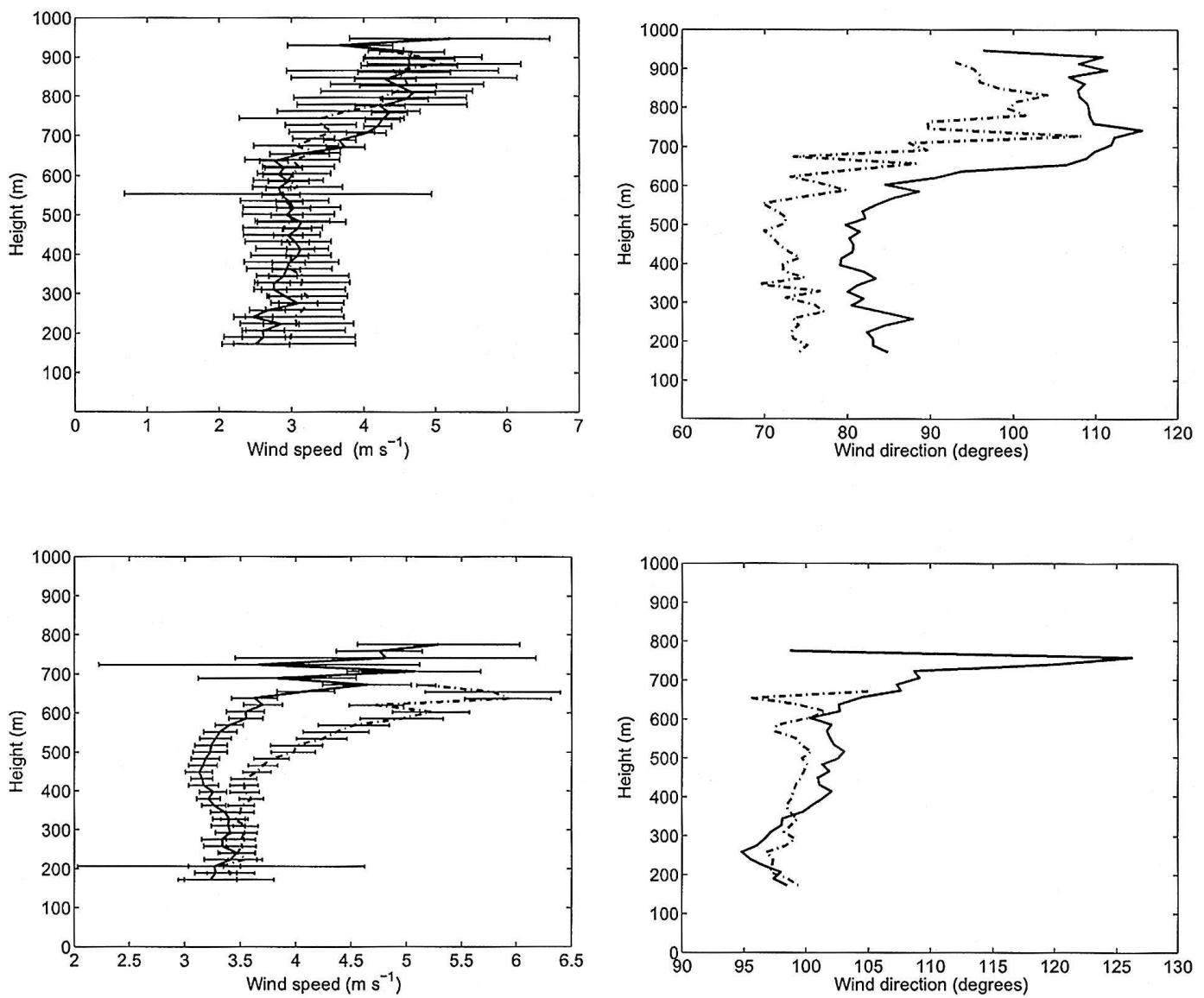

FIG. 9. (top) Speed with indicated (left) error bars and (right) direction of horizontal wind obtained from lidar VAD scans at 0926 (full black line) and 1156 (dashed black line) UTC 23 Jun. (bottom) Corresponding data for 1440 (full black line) and 1719 (dashed black line) UTC 23 Jun.

near-clear-sky boundary layers or a moderately unstable ABL associated with partial cloudiness (see Garratt 1992, p. 184), and it usually corresponds to the top of a relatively well-mixed layer. During our observation period, we noticed scattered clouds embedded in the elevated aerosol layer. Therefore, if the bottom of the aerosol layer is used to estimate $z_{i}$, it will be consistent with Garratt's definition.

Another common way to determine $z_{i}$ is to locate the increase of virtual potential temperature $\theta_{v}$ at the top of the mixed layer in radiosonde profiles (see Fig. 3 and Deardorff 1972; Stull 1988). However, because of the horizontal drift of the radiosonde, the profile of $\theta_{v}$ is affected by the presence of convective updrafts and downdrafts. Therefore, the estimate of $z_{R}$ usually is not representative above the launch site. Using active remote sensing, a higher temporal resolution of boundary layer data can be obtained, leading to better sampling statistics of the instantaneous boundary layer height and thus to a better estimate of the mean height $z_{i}$. For this purpose, either radar wind profilers (e.g., Angevine et al. 1994) or lidar systems can be used (Boers and Eloranta 1986). Whereas the radar reflectivity measurements are sensitive to the moisture gradient at the top of the CBL, the lidar backscatter measurements are sensitive to a change of aerosol particle properties. In the work by Cohn and Angevine (2000) it was shown that determinations of the instantaneous depth of the CBL from these two sources agree very well in the case of a boundary layer with high aerosol content that significantly decreases in the free troposphere.

In general, changes in the lidar particle backscatter profile can be due to a variation in number, density, size distribution and shape and can be due to complex refractive index. The backscatter coefficient is also dependent on relative humidity (Wulfmeyer and Feingold 2000). In all of these cases it is assumed that the variability of the backscatter coefficient at the top of the MBL can be used to derive an MBL top $z_{L}$ based on lidar data. For instance, using scanning lidar systems that provide range-height indicators of atmospheric backscatter, the height of the maximum of the back- 

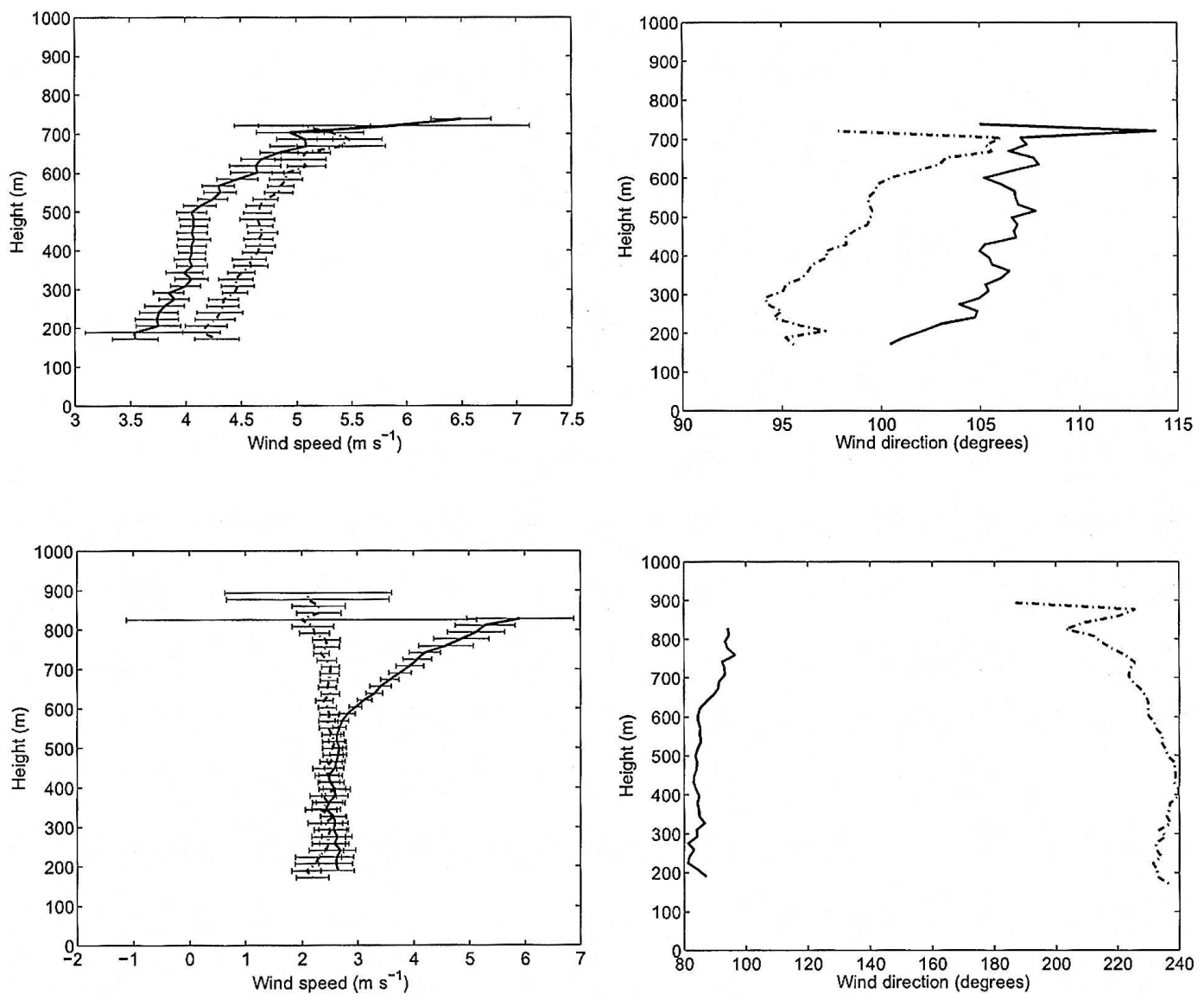

FIG. 10. (top) Same as Fig. 9, but for 1952 (full black line) and 2210 (dashed black line) UTC 23 Jun. (bottom) Corresponding data for 0104 (full black line) and 0639 (dashed black line) UTC 24 Jun.

scatter signal variance can be determined. In Piironen and Eloranta (1995), it was shown that this technique provides robust estimates of $z_{i}$. Using ground-based vertically upward pointing (Senff et al. 1994; Wulfmeyer 1999b) or airborne downward-pointing lidars (Kiemle et al. 1997), the location of the minimum of the backscatter signal gradient can be calculated and defined as $z_{L}$. An automated method for finding this location is the application of wavelet analyses (Cohn and Angevine 2000; Davis et al. 2000). In Senff et al. (1994) and Wulfmeyer (1999b) it was shown that this technique for determining $z_{L}$ usually agrees well with $z_{R}$. These findings were supported by the agreement of $z_{L}$ with radar estimates (Cohn and Angevine 2000) and the agreement of radar estimates with $z_{R}$ (Angevine et al. 1994). This chain of agreements inspires confidence in using the lidar-derived $z_{L}$ for the assessment of the MBL depth in our case as well.

However, two effects made our data analysis more difficult. First, the HRDL backscatter signals were considerably noisier in the clean MBL than were data of conventional backscatter lidars using direct direction.
Second, the MBL was characterized by clean air topped by an aerosol layer, in contrast to the cases discussed above. Therefore, we inspected very carefully the lidar data and augmented our analysis with HRDL vertical velocity, horizontal wind profile, and the radiosonde data.

We found that the detected aerosol layer was not only elevated above the top of the MBL, but actually marked the top of it. This is confirmed by the agreement of the vertical extension of updrafts in the MBL (see Figs. 4-8) but also by the agreement of the location of wind shear (see Figs. 9 and 10). Therefore, we decided to estimate $z_{L}$ by the positive maximum of the lidar backscatter signal, whereas in the typical cases discussed above the negative maximum was used. For determining $z_{L}$, no calibration was required, because this would not affect the estimation of maxima of backscatter gradients. Range correction as in directdetection lidar was not required in the coherent lidar return, because its sensitivity function was nearly constant from 200 up to $4000 \mathrm{~m}$ (confirmed by horizontally pointing measurements). The extinction of the lidar sig- 


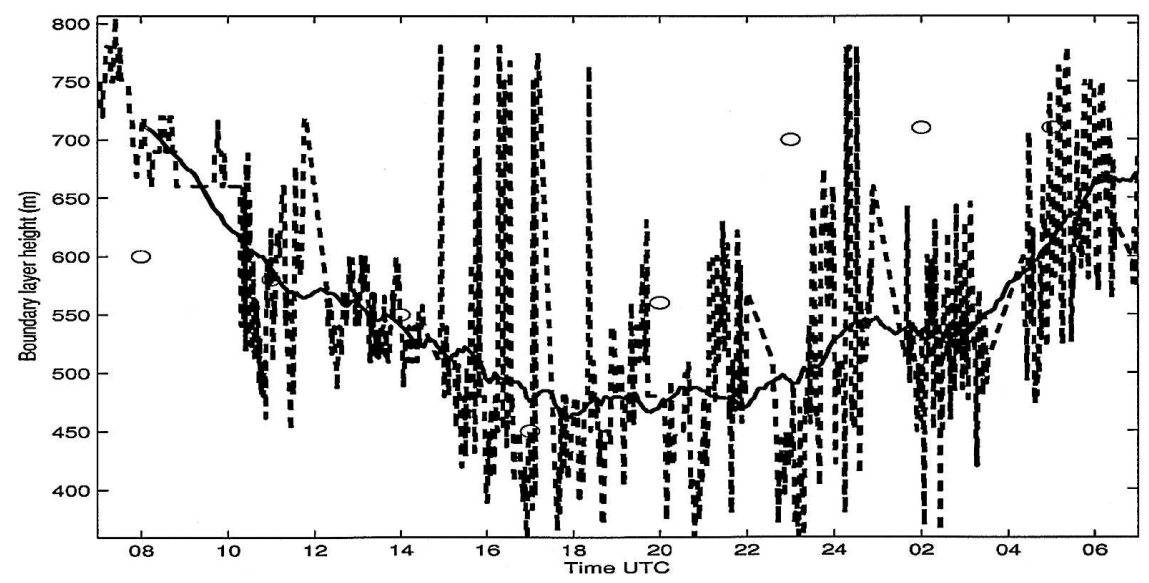

FIG. 11. Boundary layer height obtained by positive maximum of the backscatter intensity gradient from 1-min-averaged lidar data from 0700 UTC 23 Jun to 0700 UTC 24 Jun 1999 (black dashed line) and from radiosonde data (black circles). Solid black line shows the 2-h running mean of boundary layer height obtained from HRDL data for the same time period.

nal was also negligible up to the heights of interest. For the calculation of the backscatter signal gradient, we averaged the backscatter data over 1 min and used a five-point gliding average and stored the location of its maximum. This procedure reduced errors resulting from noise in the backscatter data to an acceptable level.

Figure 11 shows the results for $z_{L}$. The variability of $z_{L}$ gives also an estimate of entrainment zone thickness (Cohn and Angevine 2000). A 2-h running mean is shown that provides our best estimate of $z_{i}$. Estimates of $z_{R}$ obtained from the radiosonde data are also plotted in Fig. 11 for comparison. The maximum difference between the boundary layer heights observed with the lidar and derived from the radiosonde data $z_{R}$ is about $200 \mathrm{~m}$. However, this difference is as large as the shortterm variability of $z_{L}$ so that we believe that this deviation is due to radiosonde sampling errors. At the beginning of the observation period, $z_{i}$ was about $760 \mathrm{~m}$ and decreased to about $480 \mathrm{~m}$ at 1800 UTC. After staying constant for about $6 \mathrm{~h}$, it increased again to $640 \mathrm{~m}$ by 0700 UTC 24 June. We consequently found evidence for a diurnal variation of the MBL top with an amplitude of about $250 \mathrm{~m}$.

\section{4) Motion COMPensation}

Ship motion turned out to be an important error source for the determination of turbulent variables using HRDL. This provides a similar problem as the correction of Doppler lidar and radar data on aircrafts. Examples of the power spectrum of the vertical velocity variance derived from the HRDL data at $510 \mathrm{~m}$ (left upper panel) and $810 \mathrm{~m}$ (left lower panel) are shown in Fig. 12, together with the $-5 / 3$ slopes. An artificial con- tribution to the variance is visible at high frequencies. Its contribution must be removed in order to achieve more accurate determination of profiles of higher-order turbulent moments.

Comparison of this plot and the plots of the spectra of the ship roll and pitch shown in Fig. 13 revealed that the peak seen at the small scales in the lidar data spectrum corresponds to similar peaks in the shipmovement data spectra. We performed correction for this motion using the procedure explained below.

The platform roll, pitch, and yaw data were available at $20-\mathrm{Hz}$ rate. The ship position data were available at 1-s time resolution. The ship coordinate system was defined as $x_{s}$ axis along center line of the ship, positive toward bow (front of the ship; $y_{s}$ axis, positive toward port (left-hand side of a ship as one faces forward); and $z_{s}$ axis, positive up. Positive roll angle $\alpha$ is defined as right-hand rotation about the $x_{s}$ axis (the rotation in $y_{s}-z_{s}$ plane, positive when the port side is up). It takes on values $[-\pi / 2, \pi / 2]$. Positive pitch $\beta$ is defined as right-hand rotation about the $y_{s}$ axis (the rotation in $x_{s}-z_{s}$ plane, positive when the bow is down). It takes on values $[-\pi / 2, \pi / 2]$. Yaw $\gamma$ is defined as rotation about the $z_{s}$ axis (the rotation in the $x_{s}-y_{s}$ plane; positive is opposite of conventional heading). It takes on values [0, $2 \pi]$.

The lidar measures a projection of the velocity vector onto the beam, which can be written as

$$
\begin{aligned}
V_{b}(z, t)= & u(z, t) \cos \varphi(t) \sin \lambda(t)+v(z, t) \cos \varphi(t) \cos \lambda(t) \\
& +w(z, t) \sin \varphi(t)
\end{aligned}
$$

Here $z, \lambda$, and $\varphi$ define the coordinates of the beam in the world frame relative to the ship location. To trans- 

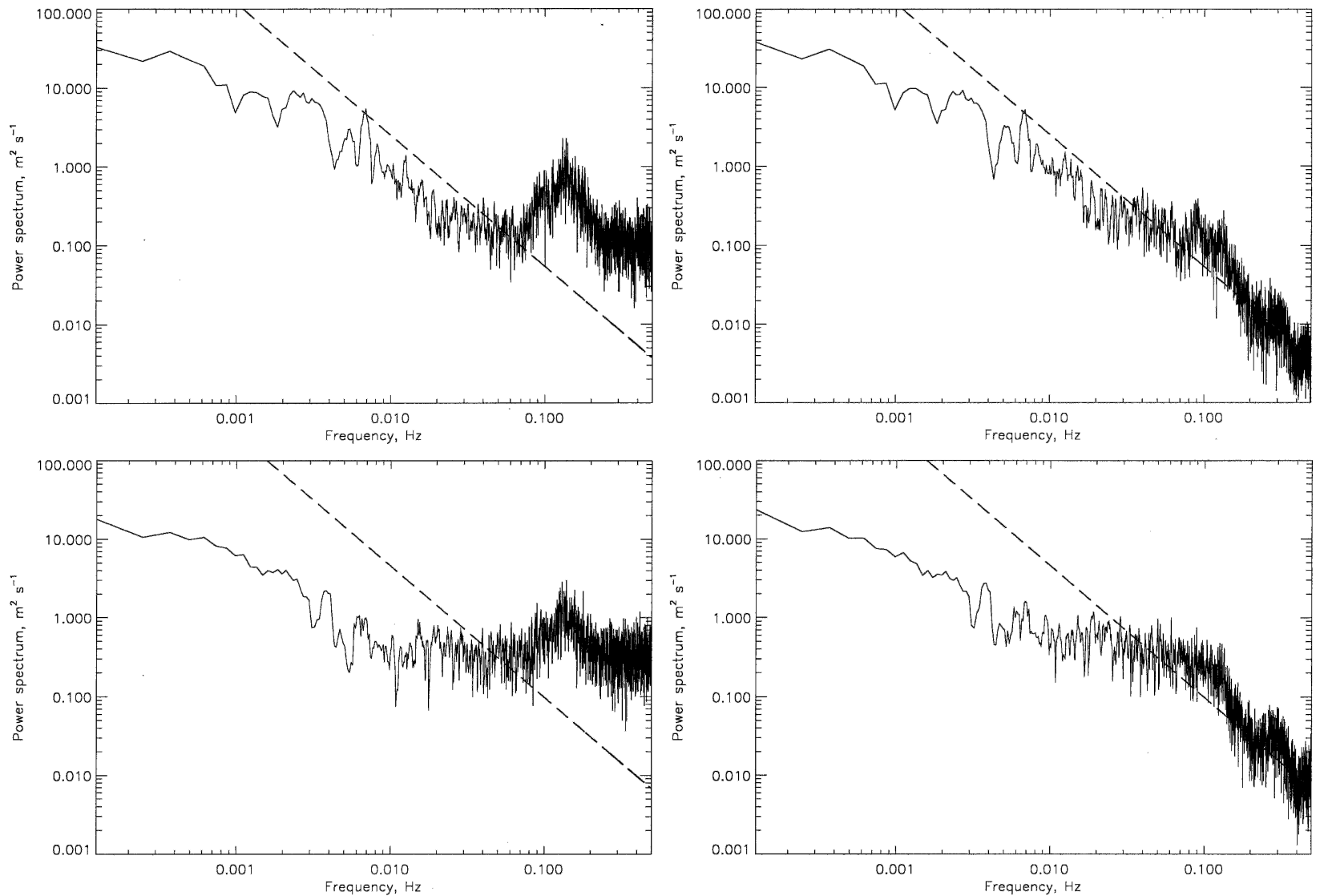

FIG. 12. Log-log plots of (top left) variance spectra of vertical velocity data at $510 \mathrm{~m}$ and (top right) data corrected for motion of the ship. (bottom) Corresponding spectra at $810 \mathrm{~m}$. All variance spectra are normalized to the total variance in the time domain and averaged using a five-point moving average. The time period used in calculation was from 1217 to 1432 UTC 23 Jun 1999. The $-5 / 3$ slopes are also plotted.

fer the coordinates of the beam from the ship frame to the world frame relative to ship location,

$$
\left[\begin{array}{c}
r \cos \varphi(t) \sin \lambda(t) \\
r \cos \varphi(t) \cos \lambda(t) \\
r \sin \varphi(t)
\end{array}\right]=\mathbf{R}_{\alpha, \beta, \gamma}^{\mathrm{T}}(t)\left[\begin{array}{c}
r_{s} \cos \varphi_{s}(t) \sin \lambda_{s}(t) \\
r_{s} \cos \varphi_{s}(t) \cos \lambda_{s}(t) \\
r_{s} \sin \varphi_{s}(t)
\end{array}\right]
$$

is used, with

$$
\begin{aligned}
\mathbf{R}_{\alpha, \beta, \gamma}(t)= & {\left[\begin{array}{ccc}
1 & 0 & 0 \\
0 & \cos \alpha(t) & \sin \alpha(t) \\
0 & -\sin \alpha(t) & \cos \alpha(t)
\end{array}\right] } \\
& \times\left[\begin{array}{ccc}
\cos \beta(t) & 0 & \sin \beta(t) \\
0 & 1 & 0 \\
-\sin \beta(t) & 0 & \cos \beta(t)
\end{array}\right] \\
& \times\left[\begin{array}{ccc}
\cos \gamma(t) & \sin \gamma(t) & 0 \\
-\sin \gamma(t) & \cos \gamma(t) & 0 \\
0 & 0 & 1
\end{array}\right] .
\end{aligned}
$$

Here $\alpha$ is roll angle, $\beta$ is pitch, $\gamma$ is yaw, and the coordinates of the beam in the ship frame are defined through $r_{s}, \lambda_{s}$, and $\varphi_{s}$.

Two methods for compensation for the ship motion were considered. The first method used (1) to calculate $w(z, t)$ and assumed that the velocities $u$ and $v$ were constant through the time period of about $2 \mathrm{~h}$ during which vertical velocity measurements were being taken. Profiles of horizontal velocities used in (1) were calculated from the VAD scans that were available before and after each 2-h block of vertical velocity measurements. This procedure did not allow the removal of the spectral peak at high frequencies, however.

The second method used measurements at four consecutive times and assumed that $u, v$, and $w$ remained unchanged during these $4 \mathrm{~s}$. Values of $\alpha, \beta$, and $\gamma$ were taken as measured (i.e., their values varied during the 4-s time period) while $u$, $v$, and $w$ remained unchanged. By first removing $w$ from the first two and the second two equations, $u$ and $v$ were calculated, 

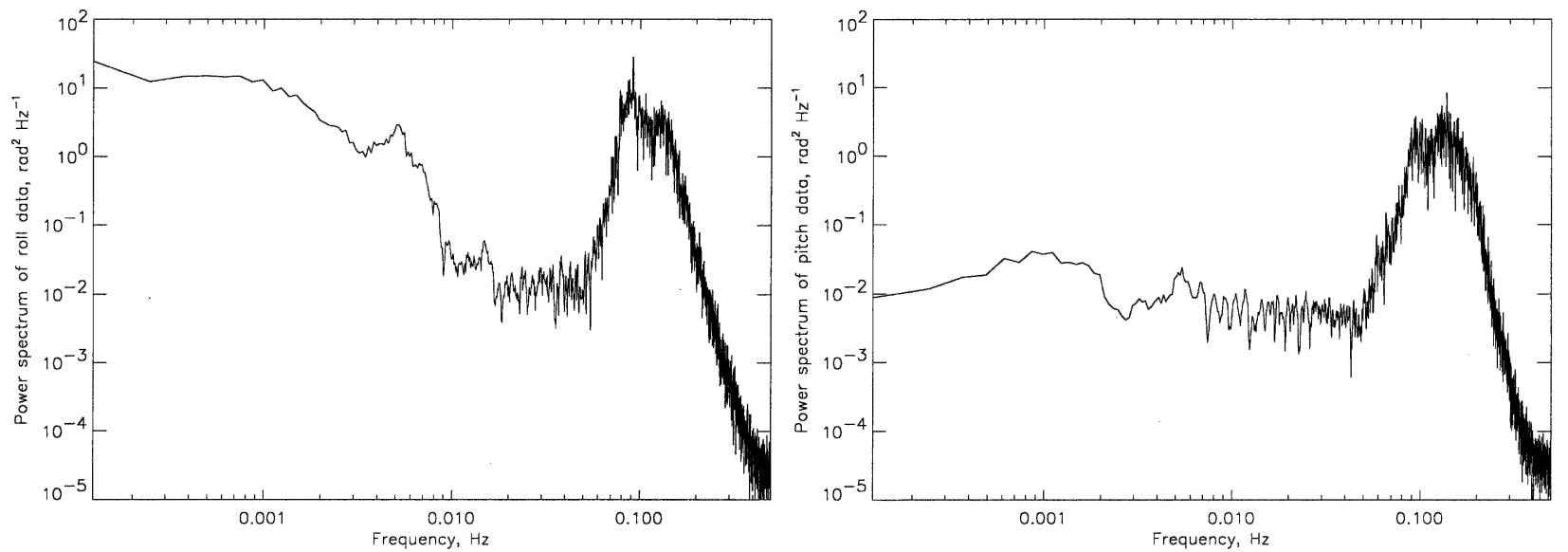

FIG. 13. Log-log plot of power spectra of ship roll and pitch data for the same time period as in Fig. 12.

and then these $u$ and $v$ were used to obtain the values of $w$ at times $t_{1}, t_{1}+1, t_{1}+2$, and $t_{1}+3$ from (1). For the calculation, five-point running-mean values of $V_{b}$ were used. As could have been expected, however, the determinant of the matrix that needs to be inverted is very small. The deviation of the elevation angle between the ship frame and the world frame relative to the ship location was up to around $1.5^{\circ}$. If the determinant was less than $5 \times 10^{-5}$, then no correction was performed, that is, if the deviation of azimuthal angle was smaller then $\pm 0.4^{\circ}$, no correction was made in the original data. Throughout the $24-\mathrm{h}$ observation period, no corrections were made to only $20 \%-26 \%$ of the data.

Examples of the vertical velocity power spectrum, corrected for the ship motion, are shown in Fig. 12 for the time between 1217 and 1432 UTC 23 June 1999 at $510 \mathrm{~m}$ (right upper panel) and $810 \mathrm{~m}$ (right lower panel). In comparing these spectra with the spectra of vertical velocity variance shown on the left of Fig. 12, we can see that the peaks at high frequencies have been removed. In the next section, comparisons of the profiles of turbulent variables calculated before and after correction are shown.

\section{5) Determination of turbulent moments}

In Fig. 12, the corrected vertical velocity power spectrum in the MBL is shown, together with the one above the MBL (see Figs. 5 and 11). Both indicate a similar amount of variance so that it is very interesting to investigate the properties of the MBL and the layer above it using profiles of turbulent moments. The motion-corrected vertical velocity data were used to determine variance and skewness profiles. The deriva- tion of profiles of higher-order moments using Doppler lidar and the corresponding error analysis were based on the procedure proposed in Lenschow et al. (2000).

Four variance profiles are presented in Fig. 14. The variance values below $240 \mathrm{~m}$ were not reliable and are not plotted. In the left panel, the dashed line represents the profile obtained using the HRDL velocity data from 1217 to 1432 UTC 23 June without taking into consideration the motion of the ship. The solid line shows the profile that was obtained by applying the motion correction described in the previous section to the data in the considered time period. The correction for ship's motion was significant, and its increase with height is reasonable, because the magnitude of the correction is proportional to the horizontal wind speed.

All variance profiles are scaled in height with respect to our best estimates of $z_{i}$ (see Fig. 11) and with the convective velocity scales $w_{*}$. The convective velocity scales were calculated from the surface flux data shown in Fig. 1 and the radiosonde virtual potential temperature data (see Fig. 3). Values of $w_{*}$ decreased from 0.53 to 0.42 $\mathrm{m} \mathrm{s}^{-1}$ at 1900 UTC 23 June and then increased to 0.6 $\mathrm{m} \mathrm{s}^{-1}$ by the end of the observation period.

The sequences of variance profiles for periods from 0940 to 1148 and from 1737 to 1945 UTC 23 June 1999 and from 0138 to 0332 UTC 24 June 1999 presented in the right panel of Fig. 14 showed an increase of variance from the first profile to the third one followed by a slight decrease in the last one. Because of the large sampling errors, however, only the increase between the first two profiles is significant. Because of the vertical coherence of updrafts and downdrafts, however, we expect that their errors are highly corre- 

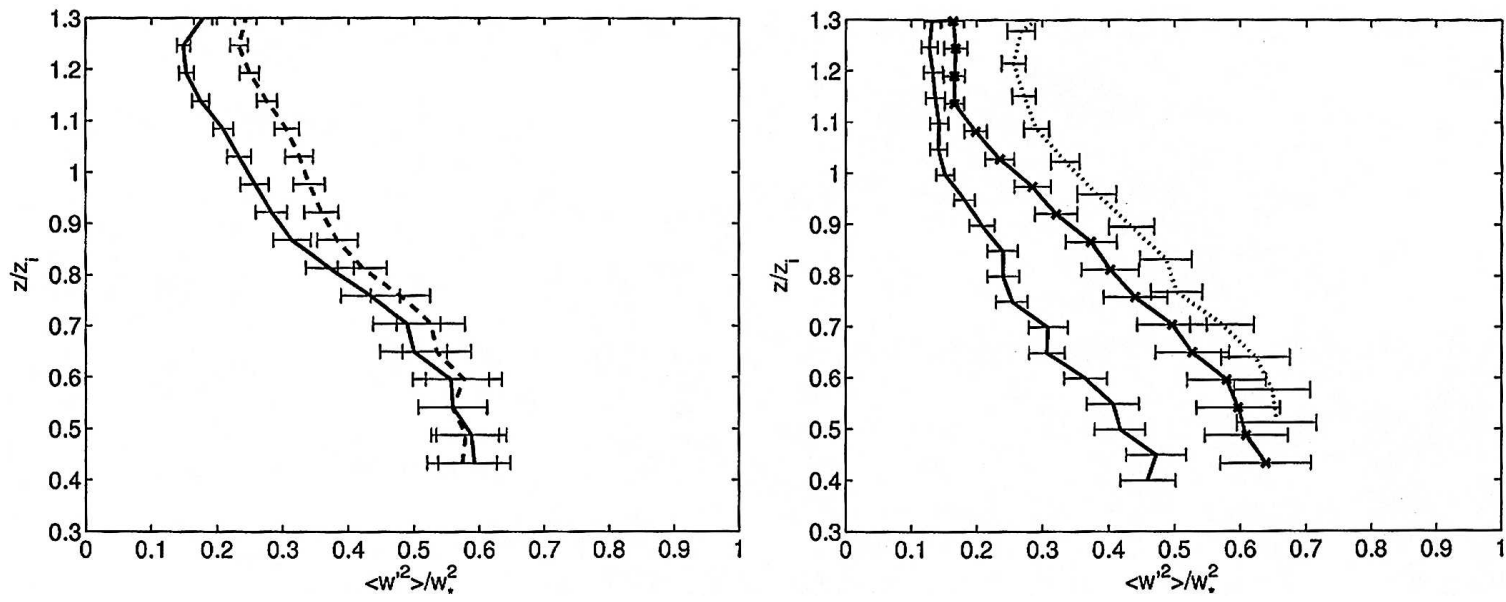

FIG. 14. (left) Variance profile obtained from HRDL vertical velocity data from 1217 to 1432 UTC 23 Jun 1999, with corresponding sampling error bars without correction for motion (dashed line) and with correction for motion of the ship (full line). (right) Variance profiles obtained from HRDL vertical velocity data from 0940 to 1148 (solid line) and from 1737 to 1945 (dotted line) UTC 23 Jun 1999 and from 0138 to 0332 UTC 24 Jun 1999 (solid line with crosses) with corresponding sampling error bars and with correction for motion of the ship. All variance profiles are scaled with respect to the best estimates of $z_{i}$ and $w_{*}$. Noise errors are negligible in all profiles.

latedin the vertical direction so that it is justified to discuss the variability of the vertical shapes of the profiles.

The location of the maximum could not be observed because of the lack of data in the near range and the low $z_{i}$. Therefore, we can just note that all of the profiles decreased from $0.4 z / z_{i}$ to $1.0 z / z_{i}$. The maximum seems to be around $0.3-0.4 z / z_{i}$ in agreement with previous measurements and similarity relationships (Lenschow et al. 1980, 2000). The large remaining variance above $1.0 z / z_{i}$ indicates remaining turbulent activity in the layer above the MBL, which is further discussed also in section $5 \mathrm{c}$.

The high resolution and accuracy of the HRDL data allowed calculations of profiles of skewness (Lenschow et al. 2000). Skewness profiles with the correction for the motion of the ship (solid line) and without it (dashed line) are shown in the left panel of Fig. 15, with corresponding sampling error bars for the same time period as the variance profiles in Fig. 14. In the right panel of Fig. 15, the sequences of skewness profiles for the same time periods as the variance profiles in Fig. 14 are shown. For the profile shown in the left panel of Fig. 15, the differences in the skewness profiles resulting from the ship motion correction are relatively small up to $0.8 z_{i}$. The skewness values vary around $0.35-0.40$. Above $0.8 z_{i}$, the two profiles begin to deviate from each other. The motion-corrected profile reaches the maximum value of 0.7 at $1.1 z / z_{i}$. The corrected skewness profile remains positive up to about $1.4 z_{i}$, whereas the uncorrected profile reaches negative values around 100 $\mathrm{m}$ lower, that is, at $1.2 z / z_{i}$.

Except for the profile measured between 0940 and 1148 UTC, the skewness profiles show a slight increase in the MBL, with a maximum around $1-1.1 z / z_{i}$. A significant amount of skewness is still present above the MBL. Values in the mixed layer are between 0.3 and 0.8. Particularly interesting is the similarity between the profiles for the data from 1217 to 1432 UTC and from 1737 to 1945 UTC 23 June 1999. These profiles show a stronger increase in values near the MBL top.

A profile showing a decrease in values near the MBL top that started between $0.8 z / z_{i}$ and $1.1 z / z_{i}$ was also observed (right panel, solid line). The change of shape of this profile may partly be due to sampling statistics.

\section{Discussion}

\section{a. Variability of MBL top}

\section{1) Comparison of MBL top MEAsurements}

The time series of the MBL top $z_{L}$ obtained from the HRDL backscatter data was compared with the radiosonde-derived MBL top $z_{R}$ (see Fig. 11). The lidar data with their higher time resolution provided also an indication about the vertical variability of $z_{L}$, which is related to the width of the entrainment zone (Cohn and Angevine 2000). Exploring the latter relationship is the subject of future studies. 

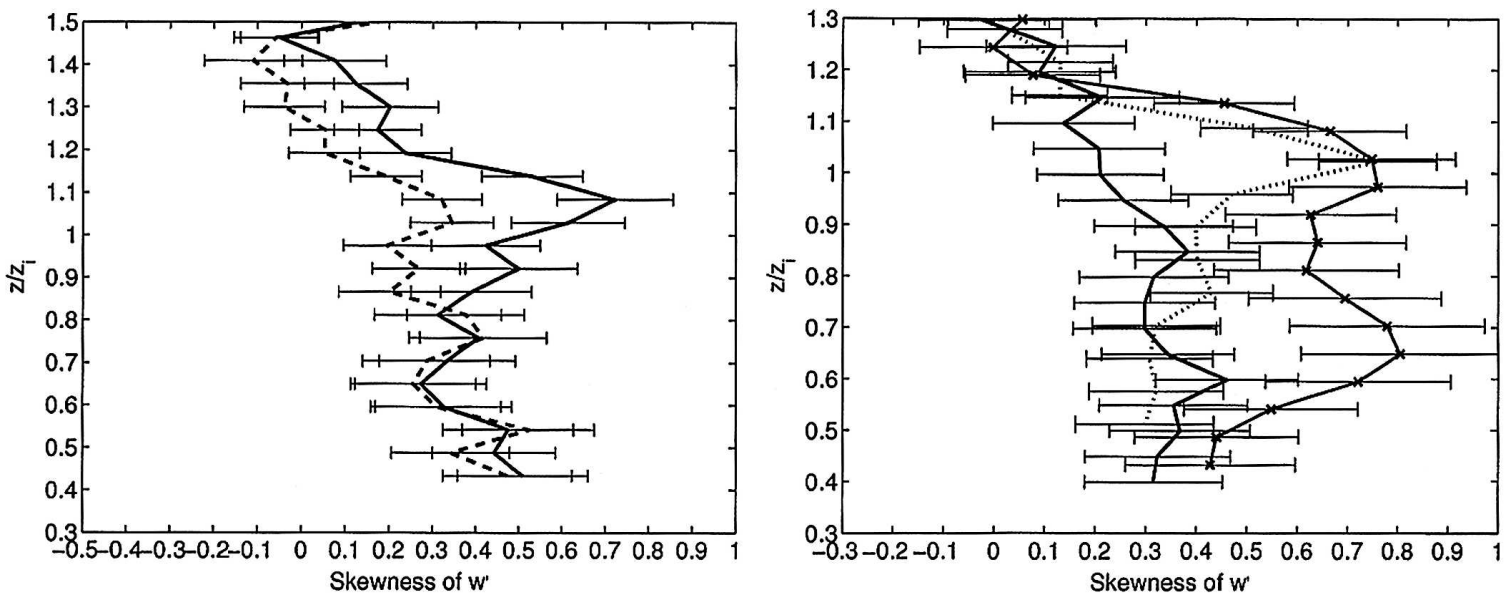

FIG. 15. (left) Skewness profile obtained from HRDL vertical velocity data from 1217 to 1432 UTC 23 Jun 1999 with corresponding sampling error bars without (dashed line) and with (full line) correction for motion of the ship. (right) Skewness profiles for data from 0940 to 1148 (solid line) and from 1737 to 1945 (dotted line) UTC 23 Jun 1999 and from 0138 to 0332 UTC 24 Jun 1999 (solid line with crosses) with corresponding sampling error bars.

Because of the different measurement techniques and the different spatial sampling, an exact agreement between $z_{L}$ and $z_{R}$ cannot be expected. However, Fig. 11 demonstrates that the radiosonde-derived MBL top stayed always in the region of the lidar-derived MBL top, including its expected vertical variability. The largest disagreement of around $200 \mathrm{~m}$ between $z_{L}$ and $z_{R}$ in Fig. 11 can be seen at 2300 and 0200 UTC on 24 June. This disagreement was probably due to noisy backscatter gradients or systematic errors caused by clouds. Although the virtual potential temperature profile shows a well-mixed boundary layer to about $700 \mathrm{~m}$ on 2300 UTC 23 June, from Fig. 3 the mixing ratio profile at that time shows a well-mixed layer to somewhat below $600 \mathrm{~m}$. In contrast, comparing the location of the wind shear obtained with the VAD scan and the boundary layer height obtained with the method described in section $4 b(3)$, for example, for profiles shown in Figs. 9 and 10, we see a good agreement between the location of wind shear and the boundary layer height. For instance, the wind speed profile in Fig. 3 shows wind shear starting at about $550 \mathrm{~m}$, which is in good agreement with the VAD wind speed profile obtained for 2210 UTC. From lidar backscatter data in Fig. 7 at 2300 UTC we see a high backscatter return between 450 and $650 \mathrm{~m}$.

\section{2) Correlation with Surface AND ATMOSPHERIC VARIABLES}

These analyses gave us confidence to study the diurnal variation of $z_{L}$. Such a variation was not detectable in the boundary layer height derived from the radio- sonde data. Figure 11 demonstrates that we found a diurnal variability of $z_{i}$ of about $250 \mathrm{~m}$. At the beginning of the observation period, $z_{i}$ was about $700 \mathrm{~m}$, and then it gradually decreased to $450 \mathrm{~m}$ until 1800 UTC and stayed constant until about 2200 UTC. It increased again to about $650 \mathrm{~m}$ from 2200 to 0700 UTC 24 June 1999.

This variability can be due to surface forcing, entrainment, or advection. According to, for example, Stull (1988), the changes of MBL depth are due to the interaction of entrainment velocity $w_{E}$ and subsidence $w_{S}$ :

$$
\frac{d z_{i}}{d t}=w_{E}+w_{S} \approx \frac{\partial z_{i}}{\partial t}
$$

In this equation, we neglected advection resulting from the horizontal homogeneous conditions during our observation period so that the total derivative of $z_{i}$ could be replaced with the storage term. In the middle of the measurement period, where $z_{i}$ was nearly constant, $w_{E}$ apparently balanced $w_{S}$. During the first phase of the observation period, $\partial z_{i} / \partial t \approx-0.01 \mathrm{~m} \mathrm{~s}^{-1}$ between 1000 and 1400 UTC. We interpret this as a reduction of $w_{E}$ during this period resulting from changing surface effects and entrainment. Because of the limited amount of data, however, it was not possible to derive the entrainment velocity from our data. Averaging the vertical wind speed of HRDL may still contain biases, which have not been investigated to date. Parameterizations of entrainment velocity usually require the measurement of the buoyancy flux at $z_{i}$ (e.g., Deardorff 1979; 

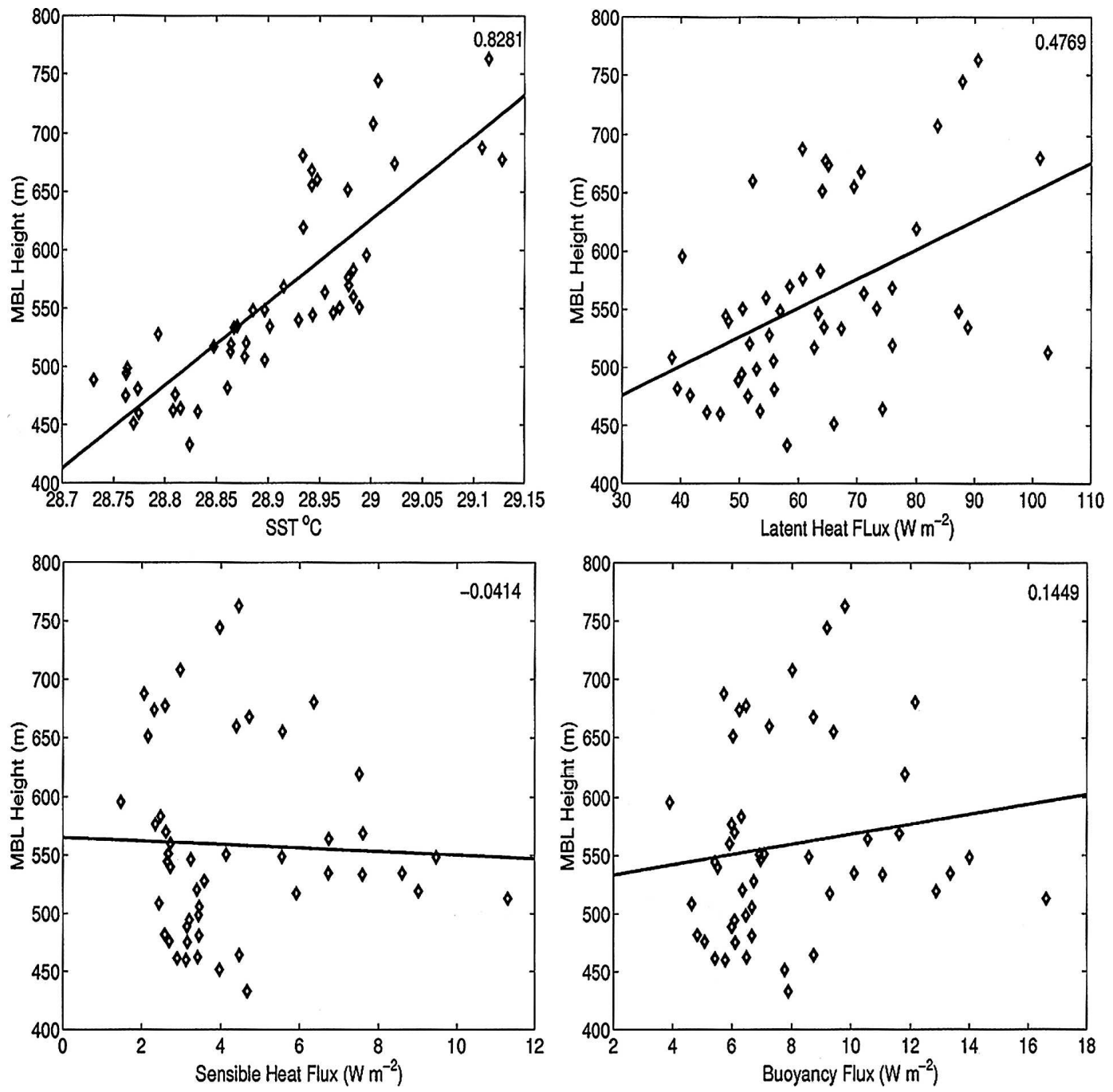

FIG. 16. Half-hour running-mean scatterplots of the MBL height versus the SST and surface fluxes. Correlation coefficients are shown (upper-right corner).

Stull 1988, with further references), which was not available.

Also, $w_{E}$ can be related to $w_{*}$ and the bulk Richardson number $\mathrm{Ri}$. It is expected that $w_{E}$ is positively correlated with $w_{*}$ and Ri. Attempts to determine Ri using the radiosonde data were not useful because of unreliable wind data (see section 5b). However, we realized that the variability of $z_{i}$ was indeed correlated with $w_{*}$. At the beginning of the time series, $w \approx 0.5 \mathrm{~m} \mathrm{~s}^{-1}$, and then it gradually decreased to $0.42 \mathrm{~m} \mathrm{~s}^{-1}$ until 1900 UTC, followed by an increase to $0.56 \mathrm{~m} \mathrm{~s}^{-1}$ until 0500 UTC 24 June. The SST data also showed a diurnal variability during the observation period (lower panel of Fig. 1).

Therefore, it was reasonable to perform correlation analyses with surface variables. Scatterplots of the HRDL MBL height dependence on the SST, sensible heat, latent heat, and buoyancy heat fluxes are shown in Fig. 16, together with the least squares line fits. As indicated by the correlation coefficient, that is, the values shown in the upper right corner of Fig. 16, the best correlations were observed between the SST and the HRDL MBL height. Some correlation also existed between the latent heat flux and the HRDL MBL height. The evolution of the buoyancy and sensible heat fluxes showed nearly no correlation with the HRDL MBL height variation.

We did expect a stronger correlation between $z_{i}$ and the buoyancy flux, because the latter is related to the convective velocity scale. We suspect that the low correlation is due to large noise in the buoyancy flux data (see Fig. 1), which are very difficult to measure, and is not due to an actual absence of correlation. 


\section{b. Comparison of horizontal wind profiles}

Figures 3, 9, and 10 present the radiosonde-derived and lidar-derived horizontal wind speed and direction profiles. The lidar data showed a realistic behavior of the wind profiles and direction with slightly increasing speeds in the MBL and wind shears at the MBL top. The variability from profile to profile in the lidar data typically amounted to $1 \mathrm{~m} \mathrm{~s}^{-1}$ and $20^{\circ}$.

In contrast, the radiosonde wind profiles often showed irregular behavior in the MBL (see Fig. 3). Therefore, we did not focus on the radiosonde wind profiles for our meteorological analyses. No profiles could be compared at the same time, but altogether the comparisons indicate that HRDL measured consistently higher wind speeds than the radiosonde data, with differences up to $1.5 \mathrm{~m} \mathrm{~s}^{-1}$. The wind directions from these two sources also showed discrepancies on the order of $20^{\circ}$. Because the surface wind speed was on the order of $2 \mathrm{~m} \mathrm{~s}^{-1}$, obviously the HRDL wind speeds are more realistic and the radiosonde wind data seem to have a systematic negative bias in the lower troposphere. Reasons for this effect can be GPS multipaths resulting from reflection at the ship's structure.

\section{c. Higher-order moments}

After correction for ship's motion, vertical velocity variance and skewness profiles were determined during four different time periods. In the MBL, the order of magnitude of the variance profiles (about 0.6) is in agreement with previous observations (Mayor et al. 1997; Wulfmeyer et al. 1998, 2000; Lenschow et al. 1980; Sorbjan 1991; Lenschow et al. 2000), as well as with large-eddy simulation (LES) results (Moeng and Wyngaard 1984; Schmidt and Schumann 1989; Sorbjan 1990). Here, we are investigating whether the shape of these profiles is in agreement with previous observations in the MBL as well as in the layer above the MBL. In Mayor et al. (1997), Wulfmeyer et al. (1998), and Lenschow et al. (2000) Doppler lidar data were used, which showed a similar shape of the profile in the MBL. In these cases a data analysis above $z_{i}$ was not possible because of too-large noise, however. In Sorbjan (1991) and Wulfmeyer et al. (2000), measurements were presented that extended above the MBL, but the turbulent structure above $z_{i}$ was not discussed.

We further investigated the shape of the variance profiles above the MBL using the familiar similarity relationship, which was derived by measurements in the MBL (Lenschow et al. 1980). This relationship only uses $w_{*}$ and $z_{i}$ as scaling parameters. We found reasonable agreement in the mixed layer; however, this profile showed a sharper decrease with height and reached zero at about $1.2 z / z_{i}$, in contrast to our observations. Sorbjan (1991) and Wulfmeyer et al. (2000) already argued that in the entrainment zone the variance profiles must be influenced by inversion-layer scaling parameters. Sorbjan (1991) derived an expression where the variance increases in the presence of wind shear. Unfortunately, we were not able to investigate this relationship in more detail because we did not measure the flux Ri, which is a part of Sorbjan's equation.

Profiles of skewness were also derived. All skewness profiles are positive throughout the MBL, which is expected because of the transport asymmetry in skewed turbulence (Moeng and Rotunno 1990; Wyngaard and Weil 1991; Schumann 1993). The values in the mixed layer varied between 0.35 and 0.4 during most of the nighttime period and between 0.5 and 0.7 during the daytime, with a maximum for the data for 0138-0332 UTC. Previous in situ measurements demonstrated similar values of about $0.4-0.5$ in the MBL (Lenschow et al. 1980; Lemone 1990; Sorbjan 1991). The results presented in Mayor et al. (1997), Wulfmeyer et al. (1998), and Lenschow et al. (2000), however, generally indicated a slight increase of the skewness up to about $0.9 z / z_{i}$, whereas the in situ data were constant in the MBL. Our Doppler lidar measurements also show this increase in almost all cases, but the maximum was shifted to about $1.0-1.1 z / z_{i}$. In principle, these results agree with LES results discussed in Schmidt and Schumann (1989), Moeng and Rotunno (1990), Sorbjan (1991), and Schumann (1993), except that here the maxima of the skewness profile were reached at about $0.9 z / z_{i}$. In one case, we observed a decrease of skewness close to the MBL top. The reason for this behavior is not known, but we expect that the skewness was strongly influenced by the more complicated doublelayer structure of the lower troposphere. Further measurements and LES simulations of wind shear and cloud condensation in a trade wind layer are needed to make more detailed comparisons possible.

The question arises as to whether we observed a vertical structure of the lower troposphere similar to that published in Russell et al. (1998). In this publication, where results of the first Aerosol Characterization Experiment (ACE1) campaign were presented, an MBL was observed with a vertical extent similar to that during Nauru99, capped by a second layer up to a height between 1400 and $1900 \mathrm{~m}$ with a pronounced temperature inversion and intermittent turbulence. Russell et al. (1998) called this a "buffer layer" because bidirectional mixing between the MBL and the free troposphere was observed. In our case, we detected a second layer as well, with a significant amount of turbulence evident in the time-height plots of vertical velocity as 
well as in variance and skewness profiles. We also found evidence of downward mixing of aerosol particles during some parts of the observation period so that we can suppose that we detected the lower part of a similar vertical structure. The upper part could not be observed because of the limited range of the HRDL measurements.

However, in contrast to Russell et al. (1998), where this layer was characterized by "intermittent turbulence," we observed a strong coupling of turbulent processes between these layers in the time-height plots of vertical velocity (see Figs. 4-8). These measurements, which provided a detailed 2D view of the turbulence, were not available in Russell et al. (1998). We cannot offer proof that we observed the same meteorological situation as in Russell et al. (1998), but we point out the similarity of the convective structures in the lower troposphere. Therefore, the existence of the buffer layer is a plausible explanation of the observed data. In contrast, the variability of vertical velocity in the inversion layer cannot be explained by wave activity alone, because the time periods do not agree with estimates of the Brunt-Väisälä frequencies [see section 4b(3)]. Further MBL observations are required to analyze corresponding turbulent transport processes in detail.

\section{Summary and conclusions}

During Nauru99, a coherent Doppler lidar system was operated for several weeks on a shipborne platform. The performance of the system was very reliable, confirming the feasibility of operating such a challenging lidar system in a routine manner on a moving platform. A major achievement was the development of a new laser transmitter cavity permitting operation of the Doppler lidar transmitter with high average power (1.5 $\mathrm{mJ}$ at $200-1000 \mathrm{~Hz}$ ) and high stability. Another important feature of HRDL was a new frequency stabilization scheme allowing operational measurements for the full duration of the campaign.

A 24-h continuous measurement of lidar backscatter and vertical velocity profiles as well as VAD scans was analyzed. The data revealed a complex double-layer structure of the lower troposphere, in which a convective MBL was capped by an inversion layer showing a significant amount of turbulence.

The depth of the MBL was estimated with high resolution by calculating the maximum in gradient of the lidar backscatter signal. This method identified the bottom of an aerosol layer, which was advected at the top of the MBL. A diurnal variation of the MBL height was observed with an amplitude of about $250 \mathrm{~m}$. Extended meteorological analyses implied that this variability was determined less by large-scale forcing or mesoscale phenomena and more by changes in surface forcing as well as in entrainment. Whereas the latter could not be studied quantitatively, changes of surface forcing within the diurnal cycle were analyzed. For instance, the variation in the MBL height was highly correlated with changes in the SST.

Using the VAD scans of the HRDL data, profiles of the horizontal velocity were derived. These data were used to confirm the detection of the MBL top. Comparison of the values obtained from the HRDL data and the radiosonde data show discrepancies in the wind intensity and direction of about $1.5 \mathrm{~m} \mathrm{~s}^{-1}$ and $20^{\circ}$, respectively.

Profiles of vertical velocity were calculated after motion compensation. It was shown that correction for motion compensation was required and was significant. Vertical velocity variance and skewness profiles were derived for four time periods. In the MBL, absolute values and shapes of these profiles agreed well with results of previous studies; however, they deviated from previous results at the top of the MBL and above. This is probably due to the significant remaining turbulence in the inversion layer intensifying exchange processes. It is likely that this turbulent activity was driven by wind shear and cloud condensation processes, as observed in trade wind boundary layers (Albrecht 1979). Whether we observed the lower part of a so-called buffer layer (Russell et al. 1998) cannot be answered with certainty. In any case, we observed a strong and coupled turbulence between the MBL and the inversion layer, which led to vertical mixing of aerosol particles during several parts of the observation period.

Though we were able to investigate turbulent moments in the MBL and above, more research is required to analyze turbulent and transport processes in the lower troposphere and to understand its turbulent motion. In particular, it is important to perform more detailed measurements of inversion-layer scaling parameters to derive quantitative measurements of entrainment velocity and fluxes under these meteorological conditions. This requires the application of a synergy of large-range active remote sensing systems during future field campaigns in this region.

Acknowledgments. This work has been funded by German Research Foundation (DFG). We are thankful to Rob Newsom, Scott Sandberg, Ann Weickman, and Mike Hardesty of NOAA for providing the HRDL data and their support with respect to data acquisition. We appreciate very much the support of Christoph Senff and Alan Brewer of NOAA with data analysis software. We are grateful to Jeff Hare of NOAA for 
providing the ship-motion data. Surface and radiosonde data were obtained from the Atmospheric Radiation Measurement Program sponsored by the U.S. Department of Energy, Office of Science, Office of Biological and Environmental Research, Environmental Sciences Division.

\section{REFERENCES}

Albrecht, B. A., 1979: A model of the thermodynamic structure of the trade-wind boundary layer. Part II: Applications. J. Atmos. Sci., 36, 90-98.

Albright, M. D., E. E. Recker, R. J. Reed, and R. Dang, 1985: The diurnal variation of deep convection and inferred precipitation in the central tropical Pacific during January-February 1979. Mon. Wea. Rev., 113, 1663-1680.

Angevine, W. M., A. B. White, and S. K. Avery, 1994: Boundarylayer depth and entrainment zone characterization with a boundary-layer profiler. Bound.-Layer Meteor., 68, 375-385.

Boers, R., and E. W. Eloranta, 1986: Lidar measurements of the atmospheric entrainment zone and the potential temperature jump across the top of the mixed layer. Bound.-Layer Meteor., 34, 357-375.

Bremaud, P. J., F. Taupin, A. M. Thompson, and N. Chaumerliac, 1998: Ozone nighttime recovery in the marine boundary layer: Measurement and simulation of the ozone diurnal cycle at Reunion Island. J. Geophys. Res., 103, 3463-3473.

Cohn, S. A., and W. M. Angevine, 2000: Boundary layer height and entrainment zone thickness measured by lidars and windprofiling radars. J. Appl. Meteor., 39, 1233-1247.

Cotton, W. R., G. D. Alexander, R. Hertenstein, R. L. Walko, R. L. McAnelly, and M. Nicholls, 1995: Cloud venting-A review and some new global annual estimates. Earth Sci. Rev., 39, 169-206.

Davis, K. J., N. Gamage, C. Hagelberg, D. H. Lenschow, C. Kiemle, and P. P. Sullivan, 2000: An objective method for determining atmospheric structure from airborne lidar observations. J. Atmos. Oceanic Technol., 17, 1455-1468.

Deardorff, J. W., 1972: Numerical investigation of neutral and unstable planetary boundary layers. J. Atmos. Sci., 29, 91115 .

_ 1979: Prediction of convective mixed-layer entrainment for realistic capping inversion structure. J. Atmos. Sci., 36, 424436.

Dickerson, R. R., K. P. Rhoads, T. P. Carsey, S. J. Oltmans, J. P. Burrows, and P. J. Crutzen, 1999: Ozone in the remote marine boundary layer: A possible role for halogens. J. Geophys. Res., 104, 21 385-21 395.

Eberhard, W. L., R. E. Cupp, and K. R. Healy, 1989: Doppler lidar measurement of profiles of turbulence and momentum flux. J. Atmos. Oceanic Technol., 6, 809-819.

Garratt, J. R., 1992: The Atmospheric Boundary Layer. Cambridge University Press, $316 \mathrm{pp}$.

Grund, C. J., R. M. Banta, J. L. George, J. N. Howell, M. J. Post, R. A. Richter, and A. M. Weickmann, 2001: High-resolution Doppler lidar for boundary layer and cloud research. J. Atmos. Oceanic Technol., 18, 376-393.

Hardesty, R. M., and Coauthors, 2003: Airborne measurement of horizontal wind and moisture transport using co-deployed Doppler and dial lidars. Abstracts, Sixth Int. Symp. on Tropospheric Profiling: Needs and Technologies, Leipzig, Germany, 390-392.
Kiemle, C., G. Ehret, A. Giez, K. J. Davis, D. H. Lenschow, and S. P. Oncley, 1997: Estimation of boundary layer humidity fluxes and statistics from airborne DIAL. J. Geophys. Res., 102, 29 189-29 204.

Lemone, M. A., 1990: Some observations of vertical velocity skewness in the convective planetary boundary layer. $J$. Atmos. Sci., 47, 1163-1169.

Lenschow, D. H., V. Wulfmeyer, and C. Senff, 2000: Measuring second- through fourth-order moments in noisy data. $J$. Atmos. Oceanic Technol., 17, 1330-1347.

_ J. C. Wyngaard, and W. T. Penell, 1980: Mean-field and second moment budgets in a baroclinic, convective boundary layer. J. Atmos. Sci., 37, 1313-1326.

Mayor, S. D., 2001: Volume imaging lidar observations and largeeddy simulations of convective internal boundary layers. Ph.D. thesis, University of Wisconsin-Madison, $177 \mathrm{pp}$.

_ S. A. Cohn, D. H. Lenschow, C. J. Grund, and R. M. Banta, 1997: Vertical velocity statistics in the convective boundary layer measured by the NOAA/ERL/ETL high resolution Doppler lidar. Preprints, 12th Symp. on Boundary Layers and Turbulence, Vancouver, BC, Canada, Amer. Meteor. Soc., 19-20.

_, G. J. Tripoli, and E. W. Eloranta, 2003: Evaluating largeeddy simulations using volume imaging lidar data. Mon. Wea. Rev., 131, 1428-1452.

Moeng, C.-H., and R. Rotunno, 1990: Vertical-velocity skewness in the buoyancy-driven boundary layer. J. Atmos. Sci., 47, 1149-1162.

_ , and J. C. Wyngaard, 1984: Statistics of conservative scalars in the convective boundary layer. J. Atmos. Sci., 41, 31613169.

Piironen, A. K., and E. W. Eloranta, 1995: Convective boundary layer mean depth and cloud geometrical properties obtained from volume imaging data. J. Geophys. Res., 100, 25569 25576.

Reitebuch, O., C. Werner, I. Leike, P. Delville, P. H. Flamant, A. Cress, and D. Engelbart, 2001: Experimental validation of wind profiling performed by the airborne $10-\mu \mathrm{m}$ heterodyne Doppler lidar wind. J. Atmos. Oceanic Technol., 18, 13311344.

Russell, L. M., D. H. Lenschow, K. K. Laursen, P. B. Krummel, S. T. Siems, A. Bandy, D. Thornton, and T. S. Bates, 1998: Bidirectional mixing in an ACE-1 marine pbl overlain by a second turbulent layer. J. Geophys. Res., 103, 16 411-16 432.

Schmidt, H., and U. Schumann, 1989: Coherent structure of the convective boundary layer derived from large-eddy simulation. J. Fluid Mech., 200, 511-562.

Schumann, U., 1993: Transport asymmetry in skewed convective circulations. J. Atmos. Sci., 50, 116-119.

Senff, C., J. Bosenberg, and G. Peters, 1994: Measurement of water vapor flux profiles in the convective boundary layer with lidar and radar-RASS. J. Atmos. Oceanic Technol., 11, 85-93.

Sorbjan, Z., 1990: Similarity scales and universal profiles of statistical moments in the convective boundary layer. J. Appl. Meteor., 29, 762-775.

_ 1991: Evaluation of local similarity functions in the convective boundary layer. J. Appl. Meteor., 30, 1565-1583.

Stull, R. B., 1988: An Introduction to Boundary Layer Meteorology. Kluwer Academic, 666 pp.

Sullivan, P. P., C.-H. Moeng, B. Stevens, D. H. Lenschow, and S. D. Mayor, 1998: Structure of the entrainment zone capping 
the convective atmospheric boundary layer. J. Atmos. Sci., 55, 3042-3064.

Weckwerth, T. M., and Coauthors, 2004: An overview of the International $\mathrm{H}_{2} \mathrm{O}$ Project (IHOP_2002) and some preliminary highlights. Bull. Amer. Meteor. Soc., 85, 253-277.

Wulfmeyer, V., 1999a: Investigation of humidity skewness and variance profiles in the convective boundary layer and comparison of the latter with large eddy simulation results. $J$. Atmos. Sci., 56, 1077-1087.

- 1999b: Investigation of turbulent processes in the lower troposphere with water vapor DIAL and radar-RASS. $J$. Atmos. Sci., 56, 1055-1076.

— humidity and particle backscattering coefficient in the marine boundary layer determined with differential absorption lidar. J. Geophys. Res., 105, 4729-4741.

_ , and Coauthors, 1998: Performance and applications of the NOAA $2 \mathrm{~mm}$ high resolution Doppler lidar. 19th Int. Laser Radar Conf., NASA/CP-1998-207671/PT1, Annapolis, MD, NASA, 573-576.

—, M. Randall, A. Brewer, and R. M. Hardesty, 2000: $2 \mu \mathrm{m}$ Doppler lidar transmitter with high frequency stability and low chirp. Opt. Lett., 25, 1228-1230.

Wyngaard, J. C., and J. C. Weil, 1991: Transport asymmetry in skewed turbulence. Phys. Fluids, 3, 155-162. 